\title{
SUPPLEMENTARY INFORMATION ON
}

VISTA

by

BERNARD TSE

BECEIVED BY TIC JUL 17 19T2

June, 1972

MASTER

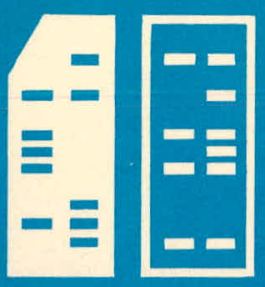

DEPARTMENT OF COMPUTER SCIENCE

UNIVERSITY OF ILLINOIS AT URBANA-CHAMPAIGN • URBANA, ILLINOIS 


\section{DISCLAIMER}

This report was prepared as an account of work sponsored by an agency of the United States Government. Neither the United States Government nor any agency Thereof, nor any of their employees, makes any warranty, express or implied, or assumes any legal liability or responsibility for the accuracy, completeness, or usefulness of any information, apparatus, product, or process disclosed, or represents that its use would not infringe privately owned rights. Reference herein to any specific commercial product, process, or service by trade name, trademark, manufacturer, or otherwise does not necessarily constitute or imply its endorsement, recommendation, or favoring by the United States Government or any agency thereof. The views and opinions of authors expressed herein do not necessarily state or reflect those of the United States Government or any agency thereof. 


\section{DISCLAIMER}

Portions of this document may be illegible in electronic image products. Images are produced from the best available original document. 


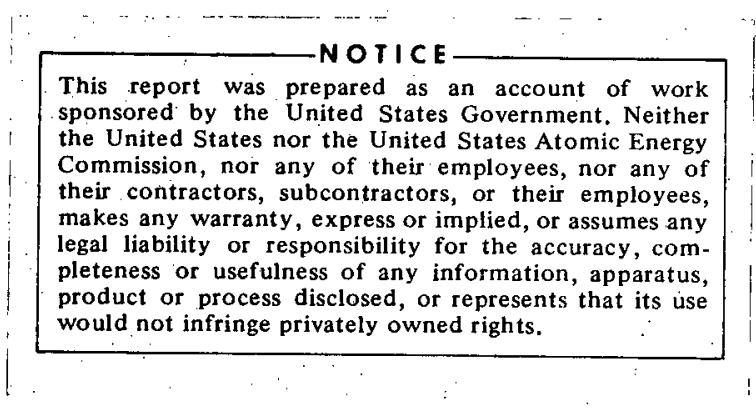




\section{Introduction}

VISTA, the Variable Interlace System for Television Applications system, as proposed by Professor W. J. Poppelbaum is a system that compresses the bandwidth of a television signal according to the rate of change of information that it is carrying. The system determines automatically the amount of information that has changed since the previous sampling period and select one of sixty-four possible scanning rates commensurate with this change. This report contains additional material that had not been included in Department of Computer Science Report No. 354 by David C. Rollenhagen and some modifications that had been made to the VISTA system since then. It is hoped that this report, together with the report by David C. Rollenhagen, will contain sufficient material to operate and to maintain the VISTA system. 


\author{
Introduction \\ Generàl Comments \\ Writing, Reading, Erasing of Video Disc \\ Read/Write/Erase Subsystem \\ Delay line \\ Delta Density Detector \\ Variable Scan Camera \\ Maintenance and Trouble-Shooting \\ Appendix
}

Page

i.

1

13

15

25

26

32 


\section{General Comments}

The system works fairly well in general. The television picture does not show much quality degraduation even when a compression of 8:1 was used. Because of the persistence of the particular CRT and the variable interlace large printed characters can still be recognized. when the compression was increased to over 20:1. Although a grey scale is supposed to be obtainable from the persistence CRT, only one or two shades of gray were obtained at best.

The television picture also exhibits a very little (about 1\%) but fairly noticeable horizontal and vertical shift when the compression ratio is switched from one to the rext. The reason for this is that owing to the shifting nature of the raster, direct coupled deflection amplifiers were used to drive the plates of the electrostatic vidicon tube. This together with the fact that the horizontal ramp is obtained by charging a selected combination of capacitors cause the slight change of DC level to the driving ramps and hence cause a shift in the picture as the bandwidth is changed.

The VISTA system performs quite well under the automatic mode. The test setup consists of a fluorescent light screen with a pattern superimposed on top. The system would automatically switch to a higher bandwidth is the light screen is slightly displaced, and after the built-in 5 second delay, would return to the origin reduced bandwidth if the picture had not been further disturbed. A reduced bandwidth with a compression ratio of $8: 1$ is used for the case when the camera is pointing to a static picture. For the automatic mode, this would be the smallest bandwidth required (and hence the largest compression) by the system. This compression ratio was chosen mainly because at this bandwidth, the quality of the picture is still excellent, without any discernable flicker at all. Depending on the degree of change of the picture, an 
appropriate higher bandwidth (and hence a low compression ratio) would be selected. A slight bump to the camera would cause the bandwidth to be raised to the 6:1 level for example, or a palm'placed into the path of the camera would cause the compression ratio to be switched back to $1: 1$.

In general the system performs fairly well. It does demonstrate the idea of bandwidth compression by reducing the scan rate and at the same time solve the flicker problem by the variable interlace. 
Writing, Reading, Erasing of Video Disc

The object of the delta density detector is to realize the function:

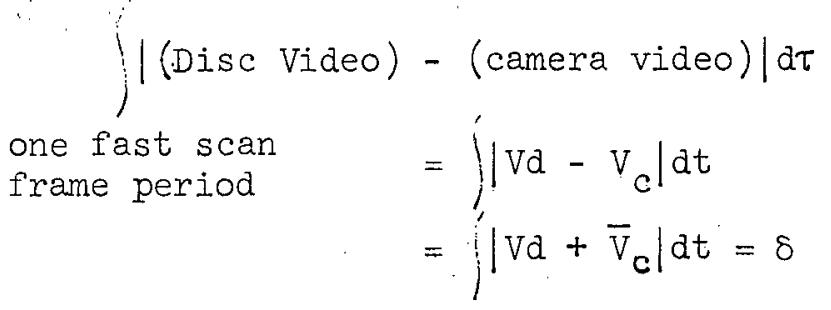

which is called the delta-density signal. The system switches between two fast scan frames and a slow scan frame. The scan rate during the slow scan mode is derived from the delta density signal which is calculated automatically during the two fast scan frames. The original scheme called for only one fast scan frame alternating between the slow scan frame. In such a scheme, three tracks of the video disc were used. During every fast scan mode one of the three tracks was erased, one was recording the incoming video from the camera, and the third was being read and the information compared with the incoming camera video to determine $\delta$. ' $\delta$ is calculated by comparing the stored video from the previous frame with the current incoming video from the camera this indicates the amount of information which changes between successive fast scan.) This necessitates a sequential switching between the three tracks as illustrated and described in section $\mathrm{A}-1$ of the appendix in the thesis (report 354). This scheme did not work well due to one difficulty. Owing to the high currents required to record video on a track of the disc, there is up to $50 \%$ intermodulation between channels. That is, if video is being recorded on one track, 50\% of this signal may appear in the signal being read out from an adjacent track. This implies that one cannot read and write simultaneously, and as a result the entire scheme of recording and reading was altered. In addition, the signal levels (both magnitude and bias) required for recording 
were difficult from one channel to another; and the signals being read off the disc differ in amplitude also. So a multiplicity of gain and level controls is needed.

\section{Writing/Reading/Erasing Sequences}

The new scheme for Writing/reading/erasing the two tracks of the video disc used is shown in Figure 1. The main point to note is that the two channels are never recording and read at the same time. The system switches between 2 fast scan frames and $\mathrm{N}$ slow scan frames (N can be set on the control panel). The delta density signal is derived during the fast scans, and it controls the compression ratio for the slow scan mode. The gating signals are described in a later section.

\section{Read/Write/Erase Subsystem}

A block diagram of this subsystem is shown in Figure 4. The camera video signal is amplified by the video amplifier which puts out 2 similar versions $\left(V_{c}\right)$ of the amplified input, and $\bar{V}_{c}$ which is $180^{\circ}$ out of phase with $\mathrm{V}_{\mathrm{C}} \cdot \overline{\mathrm{V}}_{\mathrm{C}}$ is later used in the delta density detector to be compared with the disc video stored from the previous fast scan. The two $V_{c}$ 's go one each to either one of the two bias adjusting and write gating circuit before finally going to the inputs of the 2 channels of the video disc.

The radio frequency modulated disc video signals from the two channesl go into their own respective read gates and they are then amplified and demodulated to become the disc video vd which is used in the delta density detector. A more detailed description of the individual blocks follow below. 


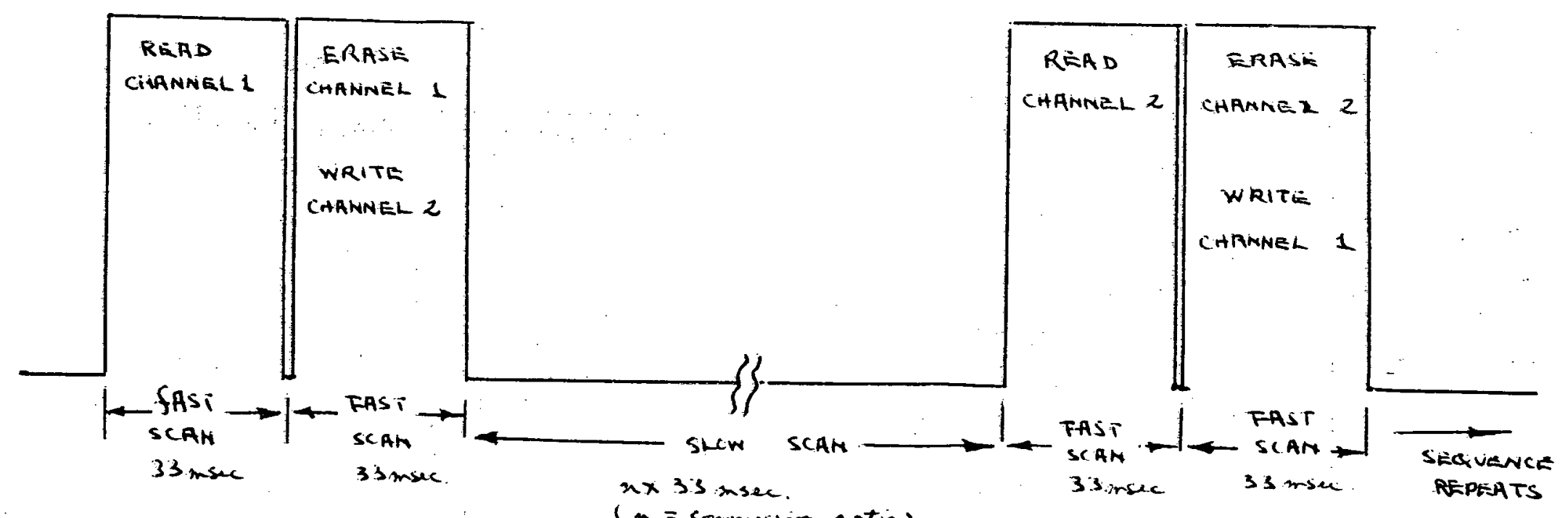

DËLATED SAMPLE
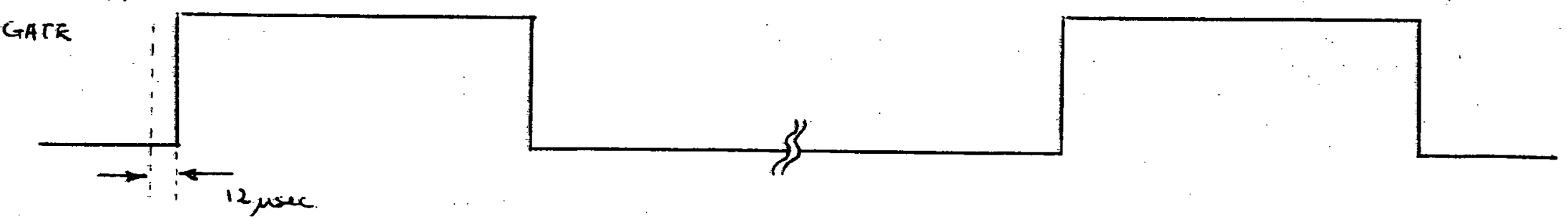

$12 \mu \mathrm{sec}$

WRITE/READ/ERASE SEQLENCE FLR XIDEC DISC:

$F / c, 1$ 


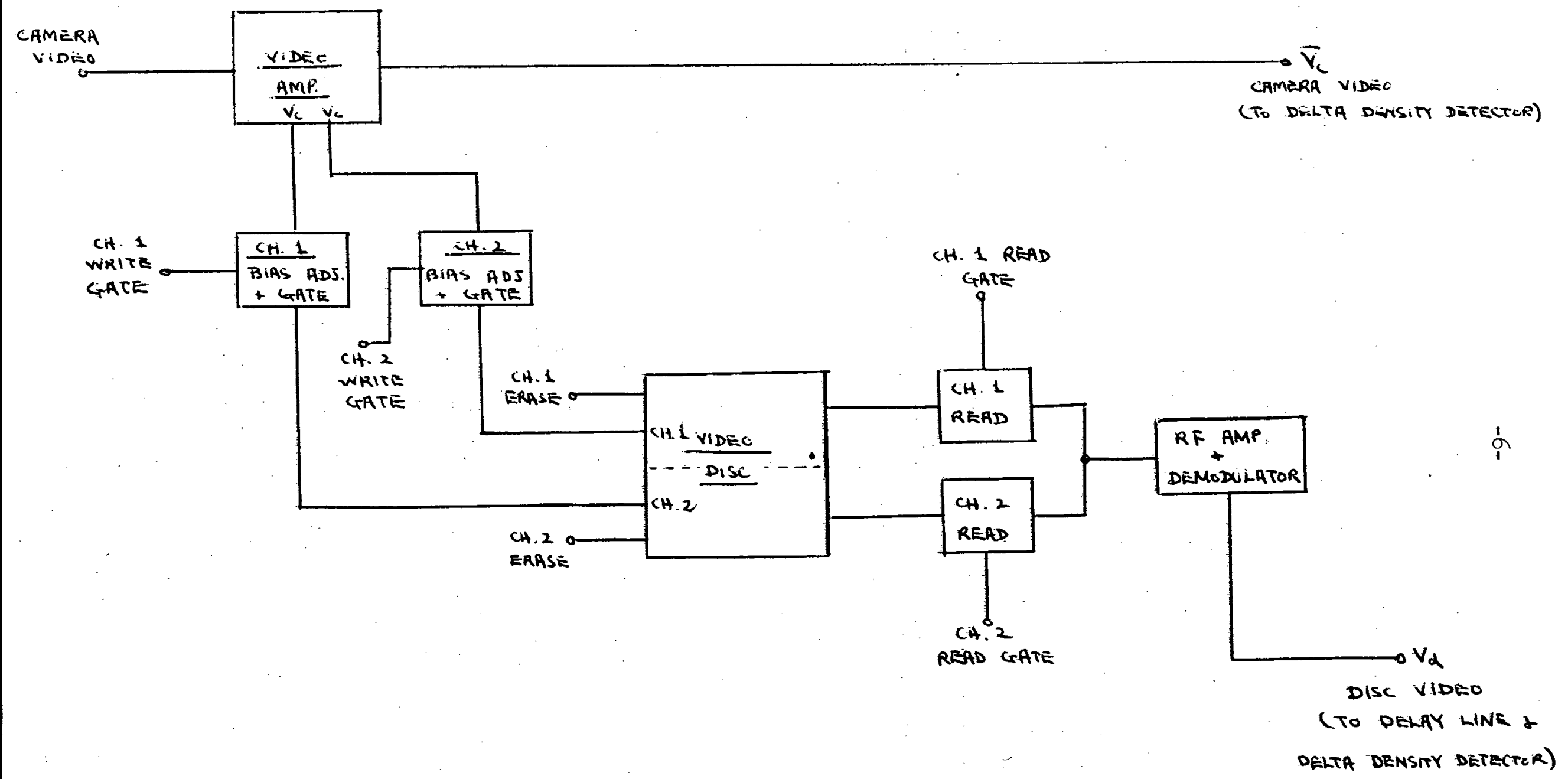

READ/WRITE/ERASE SUBSYSTEM

$F \mid G .2$ 
Camera Video Amplifier $(1469-403)$

The circuit diagram of this amplifier is shown on Figure 3 .

One $V_{c}$ output goes to the bias adjust and write gate of Channel 1 while the other $V_{c}$ goes to that of Channel 2. The loos potentiometer is the clamp adjust, the three $I K \Omega$ potentiometers adjust the amplitude of $V_{c}$ and $\bar{V}_{c} \cdot \bar{V}_{c}$ should be $180^{\circ}$ out of phase with $V_{c}$ :

Camera Video Bias Adjust and Write Gates (1469-404)

The circuit diagram is shown on Figure 4 . Two identical sets of this circuit is needed, one each for Channel 1 and Channel 2 of the video disc. The $200 \Omega$ potentiometer should be adjusted so that the video at the input of the video disc has a D.C. level of slightly less than I volt. The amplitude of the video should be adjusted by the IK $\Omega$ potentiometers of the camera video amplifier to about 0.3 to 0.5 volts.

The optimal bias and gain is very critical and varies from track to track. A trial of different values of bias and gain should be made while observing the video disc output.

This camera video is gated out to the video disc alternately at the appropriate time slot.

Erase Gate (1469-404)

The erase gate is shown in Figure 5. Again two of these are required, one each for Channel $I$ and Channel 2. For erasing, a logical "O" (O volt) should be the input, which normally stays at 4 to 5 volts. 

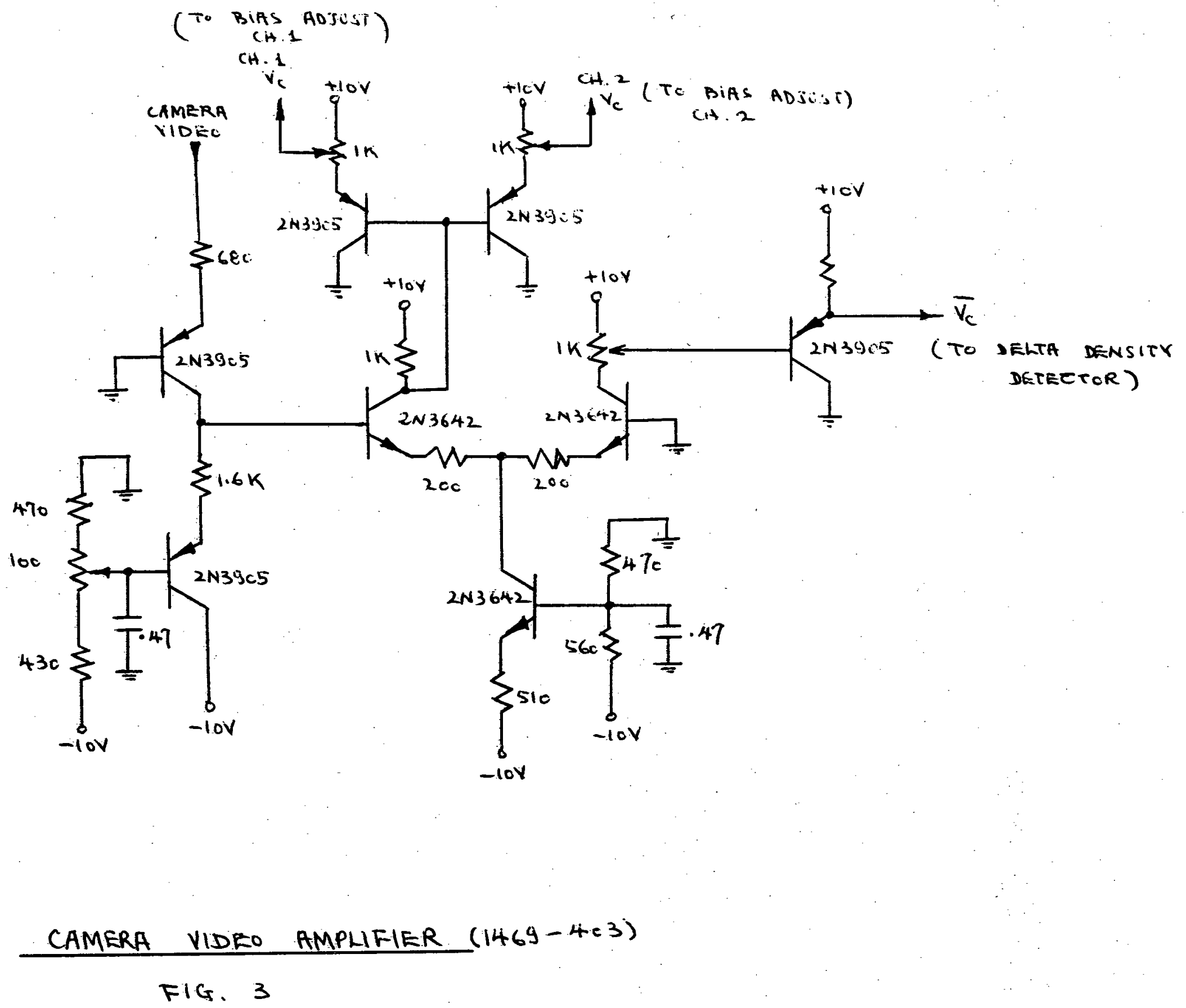


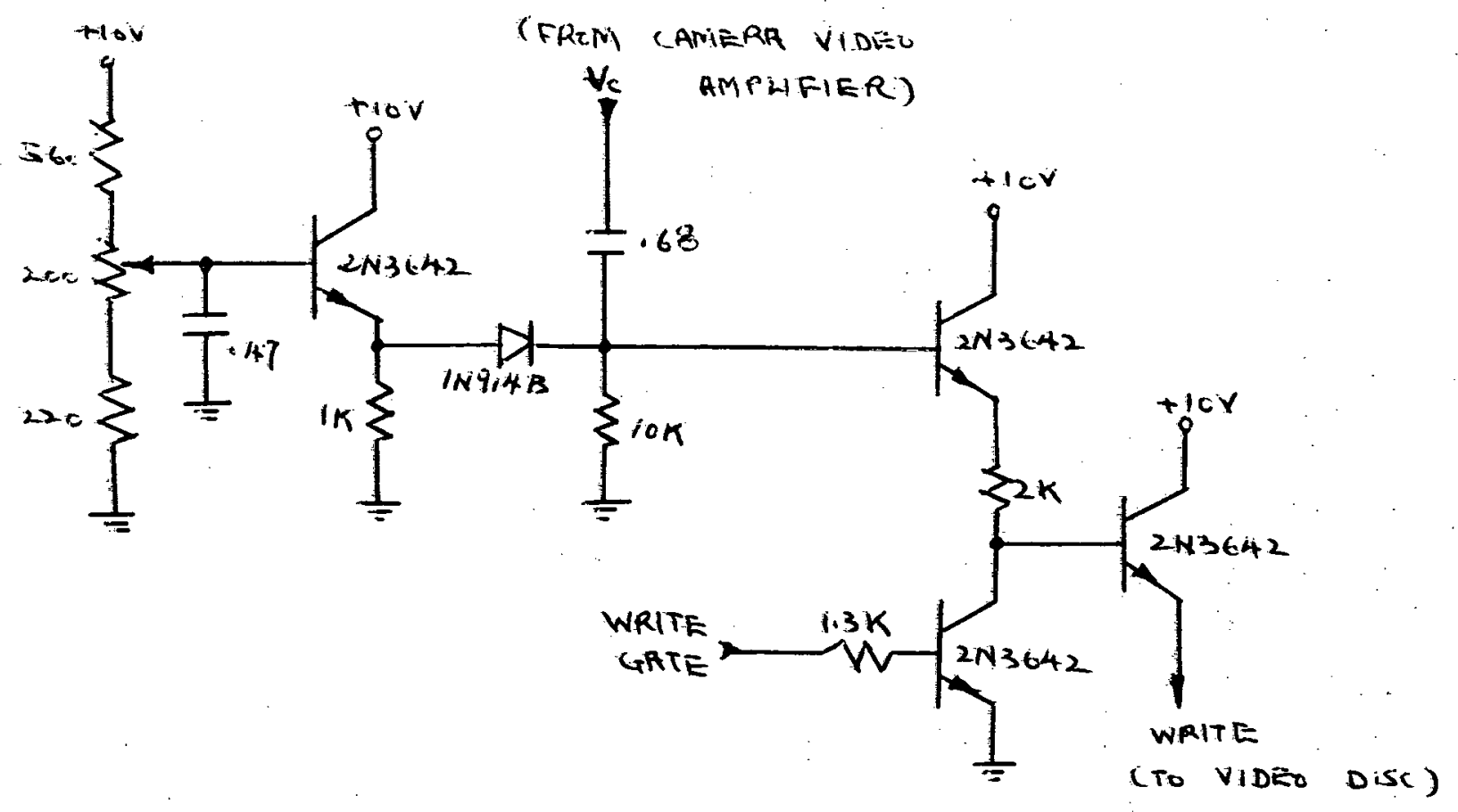

$\dot{\varphi}$

BIAS-ADJUST AND WRITE GATE (1469-404)

$$
\text { FIG. } 4
$$


Read Gates $(1469-404)$

The read gate is shown in Figure 6. Two of these are required, one for each channel. Its function is to gate the high frequency modulated disc video to the $R F$ amplifier and demodulator at the appropriate time slot. A 4 volt input would cause the disc video to be gated out. The input is grounded when no reading is desired.

RF A mplifier and Demodulator (1469-405)

This circuit is time-shared by Channel 1 and Channel 2. The circuit diagram is an Figure 7. The first two transistors are part of the RF amplifier. Following this is the demodulator and a voltage amplifier with a gain of about 5 . The output of this circuit is the disc video va, which goes to the delta density detector to be compared with $\overline{\mathrm{V}}_{\mathrm{c}}$. 

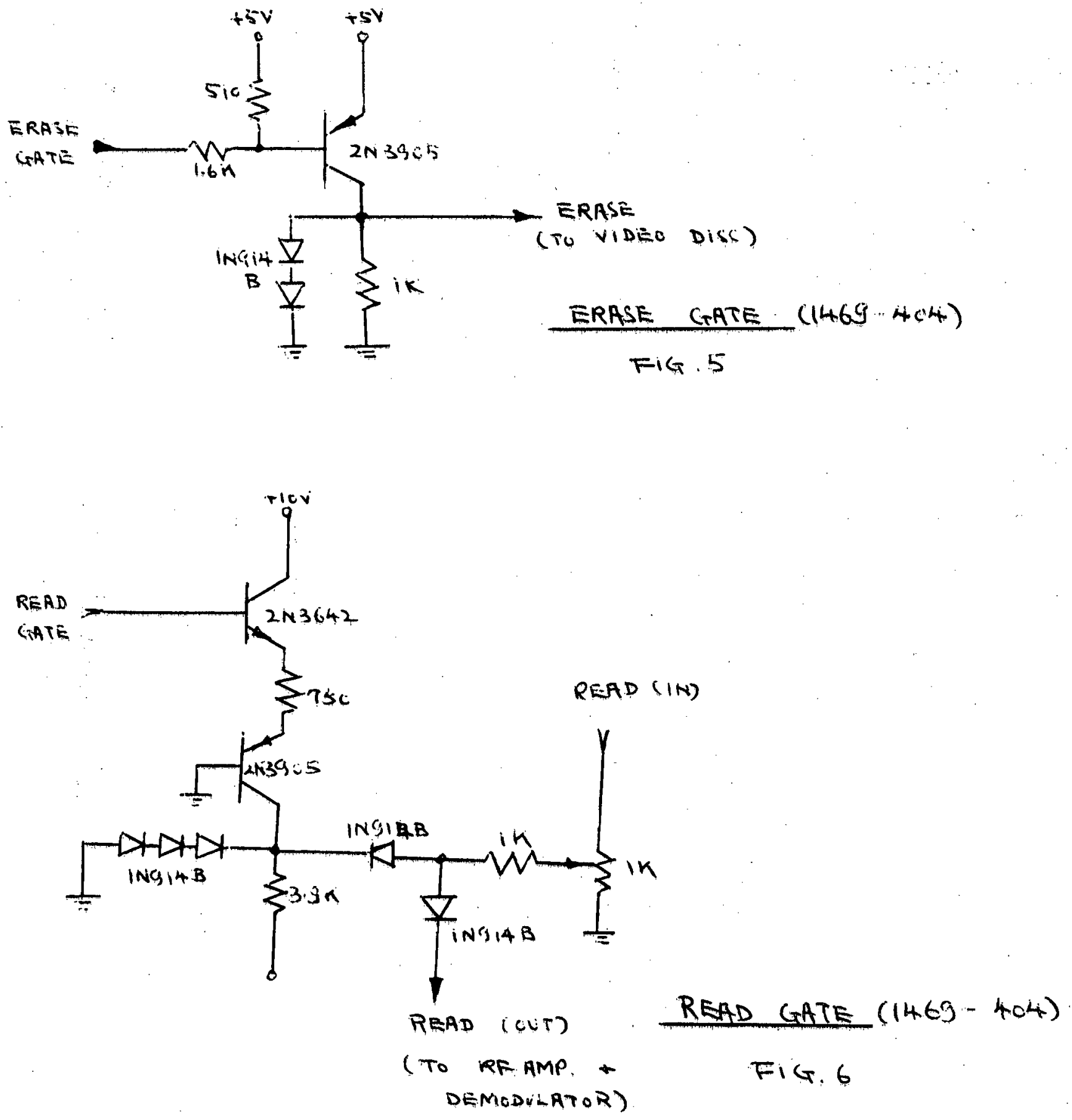


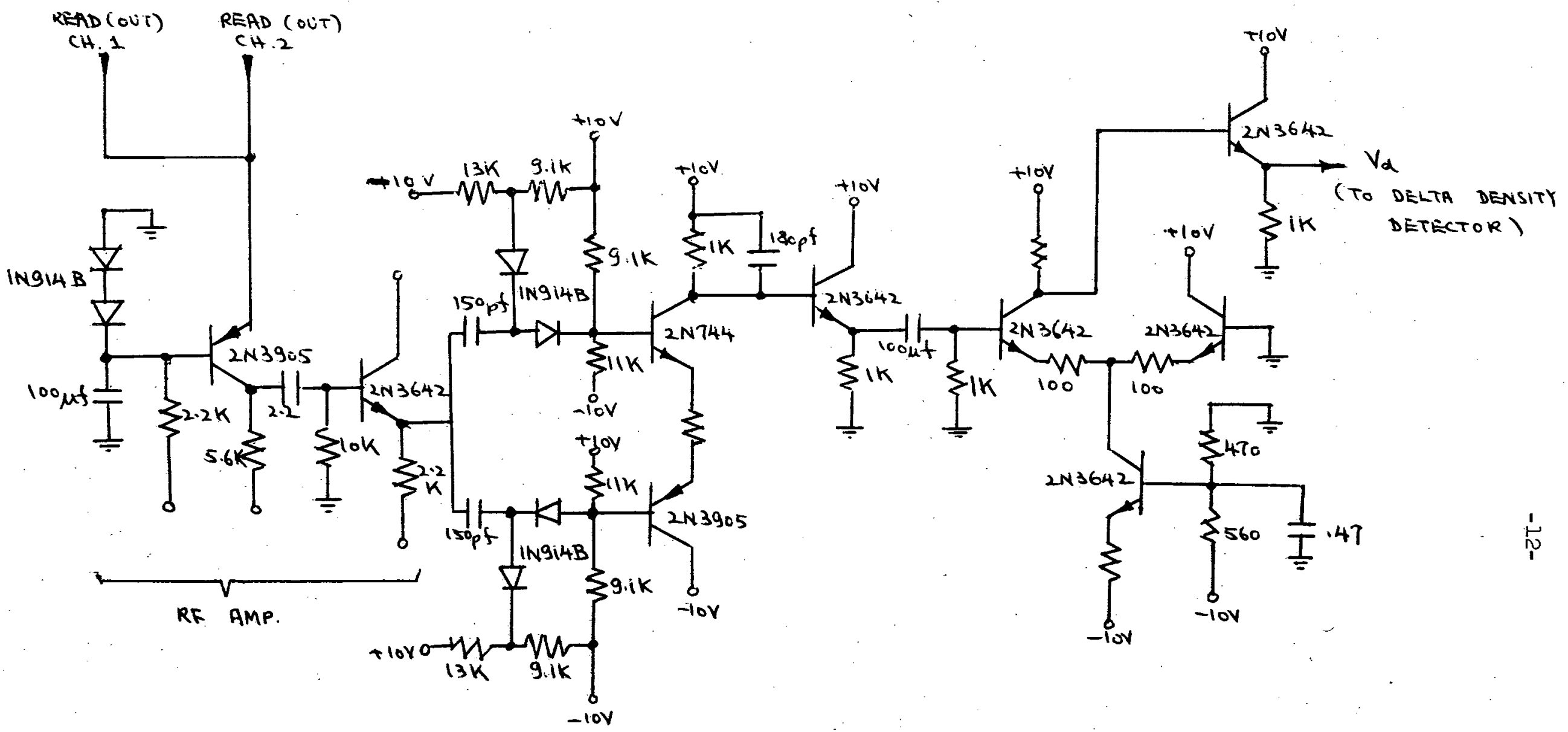

DEMODULATOR

AMP. GRIN $\approx 5$

RF AMPLIFIER AND DEMODULATOR (1469-405) Fist. $T$ 


\section{Delay Line}

In the subsystem described above, two signals, namely camera video $\bar{V}_{\mathrm{c}}$ and disc video are compared for differences at the delta density detector. The disc video has an inherent delay of slightly less than I microsecond compared to that of the camera video $\overline{\mathrm{V}}_{\mathrm{c}}$, So before comparing these two signals at the delta density detector, $\bar{V}$ has to be appropriately delayed. A 900 nanosecond delay line is used, with the proper terminations as shown in Figure 8. The input to the delay line comes from the $\bar{V}_{c}$ output of the camera video amplifier. The output goes to the delta density detector. 


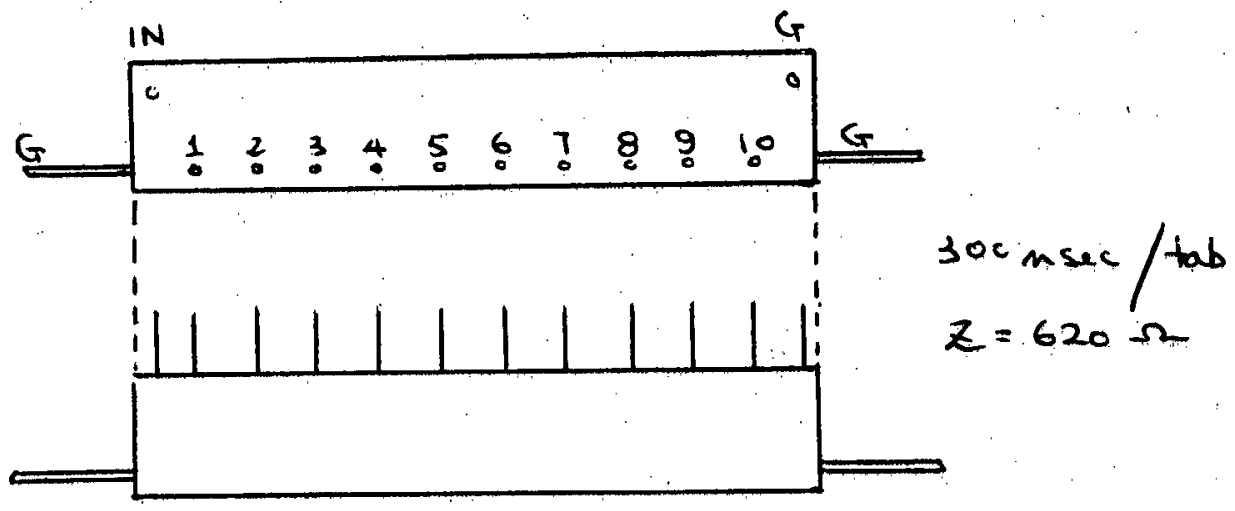

DELAY LINE $3200602-10$

CT 1825

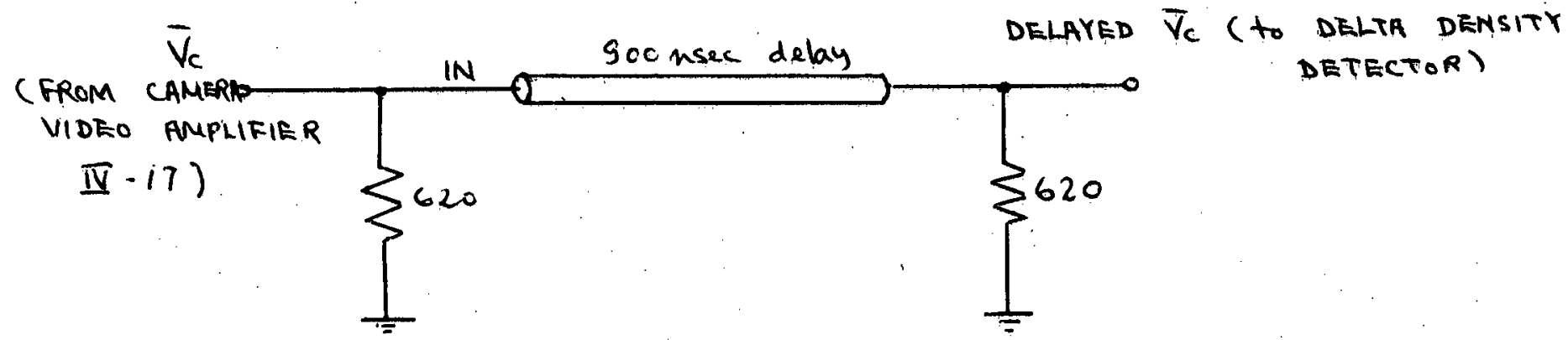

DELAY LINE

FIG. 8 
Delta Density Detector

A major change was made in the design of the delta density detector. The original design was found to be too unstable as the circuit exhibits small but fatal D. C. drifts and gain during its operation. Another source of error was that the 2 inputs to the difference detector (op. amp. 709), namely the disc video and the on-line video, have to be very critically adjusted so that they have exactly the same magnitude and D. C. levels. All these factors pointed to another design concept.

A block diagram of the final design incorporated into VISTA is shown on Figure 9. In this design, the disc video Vd (from demodulator and amplifier) and on-line video $\vec{V}_{c}$ are digitized by 2 differential comparators and their difference is detected by an EXCLUSIVE-OR circuit. This latter is gated and chopped up by the $1.5 \mathrm{MHz}$ clock signal. This is then counted by a 16 bit synchronous counter so that the difference in picture material of the 2 video frames is represented by the binary output. In order to ignore any random noise and other inaccuracies, only the 12 most significant bits of the counter are used to generate the desired delta density signal. These la bits are simultaneously converted to a ramp by the D/A converter just as they are conuntered; and at the sampling moment, the magnitude of this ramp is detected and this D. C. level is used to control the bandwidth of the video signal of the following frames.

A more detailed description and diagrams of this subsystem is described below. 


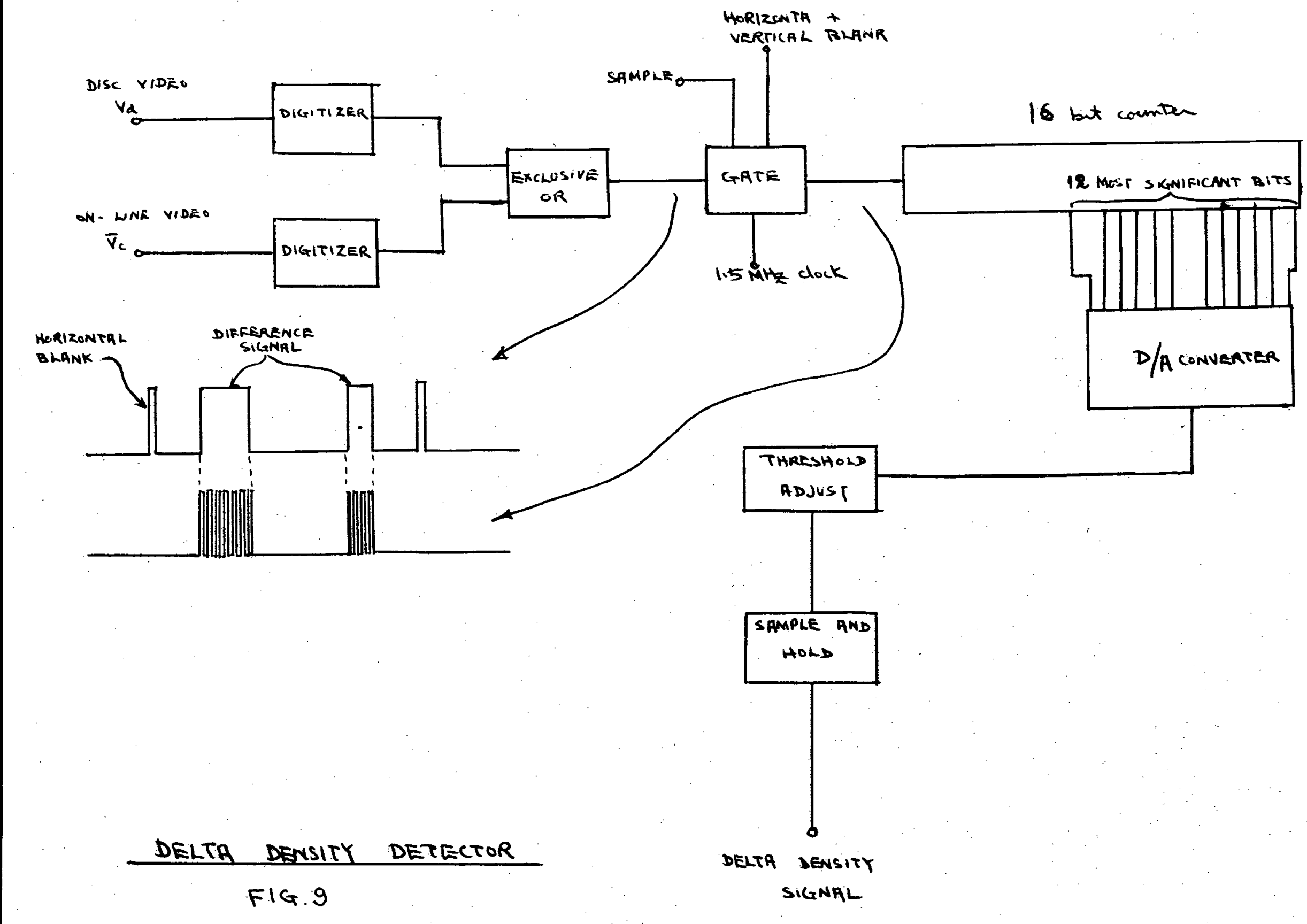




\section{Difference Detector}

The circuit diagram is shown on Figure 10. The disc video Vd from demodulator's amplifier) and the on-line video $\bar{V}_{c}$ (from delay-line) signals are digitized by the 2 differential comparators (710). The triggering levels are adjusted by the two $2000 \mathrm{ohm}$ potentiometers. The 5 2-input NAND gates following the comparators generate the EXCLUSIVE-OR of the disc video and the on-line video so that the difference of $\mathrm{Vd}$ and $\bar{V}_{\mathrm{c}}$ appears at one of the inputs of the 4-input NAND gate.

Ihis signal is gated by the delayed-sample gate, the blanking disable signal (which blanks out the horizontal and vertical blanking signals) and the $1.5 \mathrm{MHz}$ clock. This chopped signal goes to the 16 bit error counter.

\section{$1.5 \mathrm{MHz}$ Clock}

The circuit diagram is shown on Figure 11.

This consists of 2 one-shot multivibrators cross-coupled together. The timing capacitor-resistor of $Q_{1}$ controls the pulse width. That of $Q_{2}$ controls the repetition rate. The stability of this clock is not very critical.

\section{Bit Error Counter, D/A Converter and Threshold Adjust}

The circuit diagram is shown in Figure 12. Four SN74193 are connected as a 16 bit synchronous up counter. The four lower order bits are ignored so as to make the circuit insensitive to minor error that might have entered during recording, amplification or demodulation. The 12 higher order bits are summed up simultaneously as the counter is counting and the sum would appear at the output of the operational amplifier (7.41). 


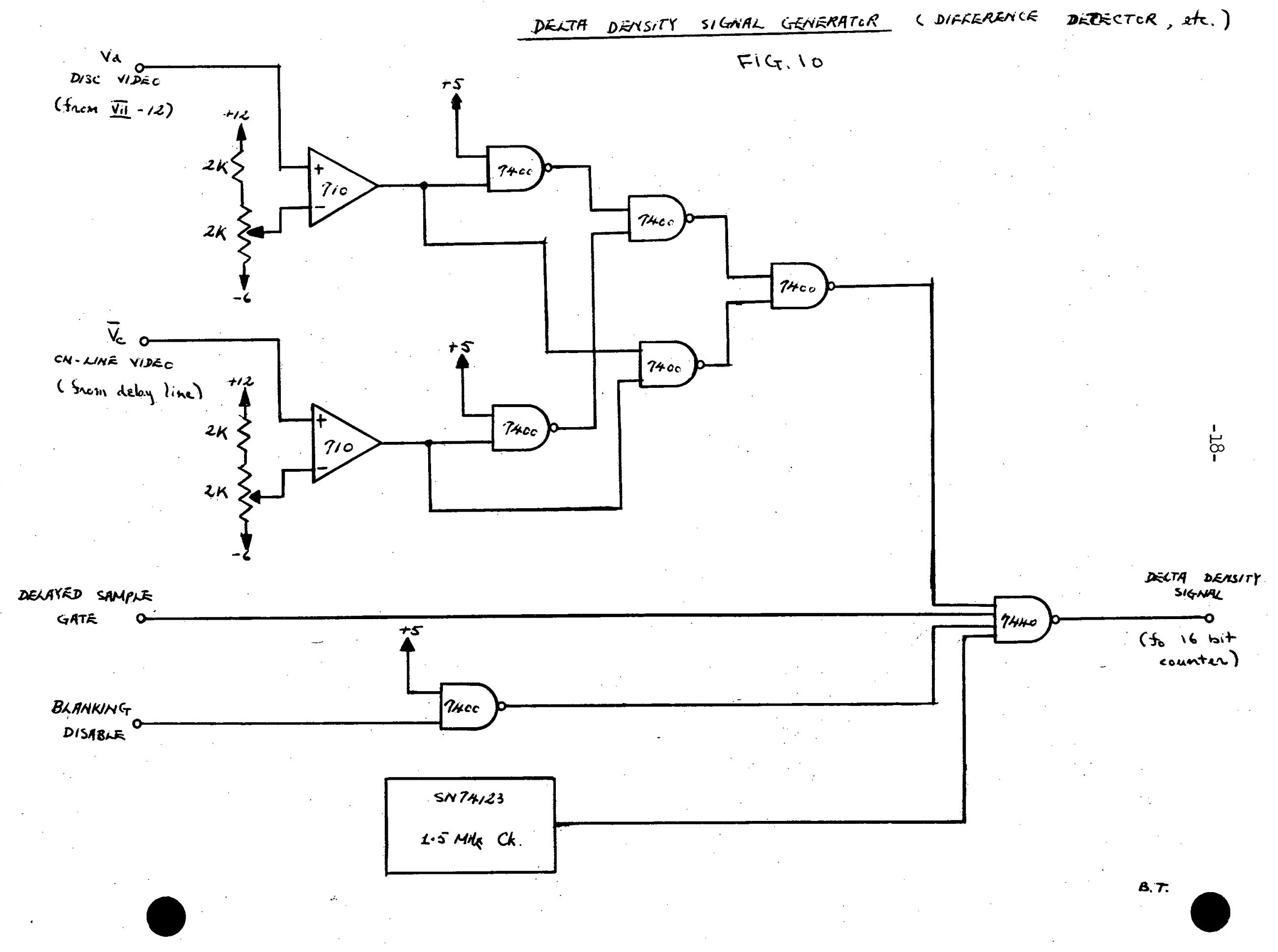


FIG. II

1.5 MHZ CLCCK

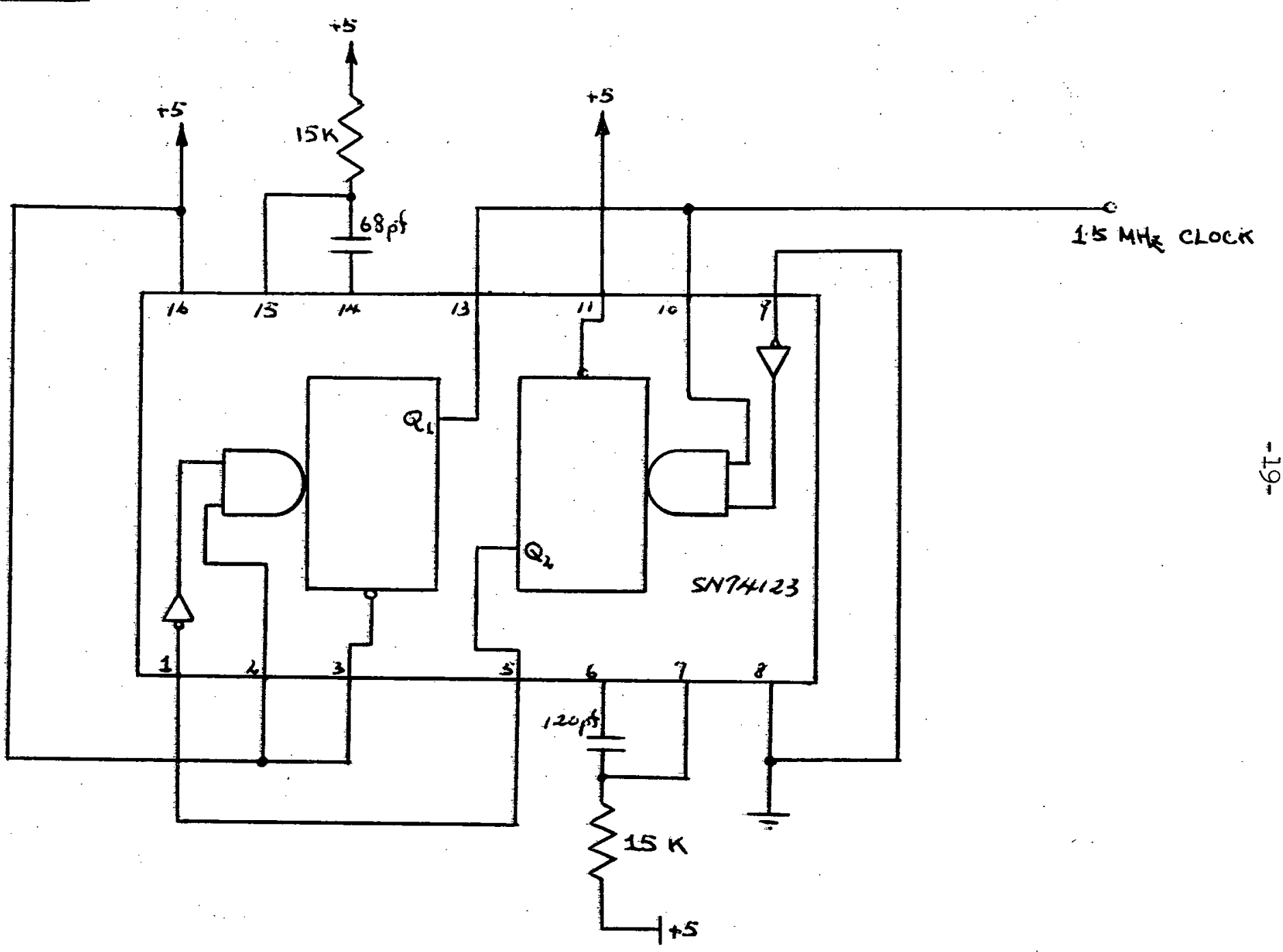




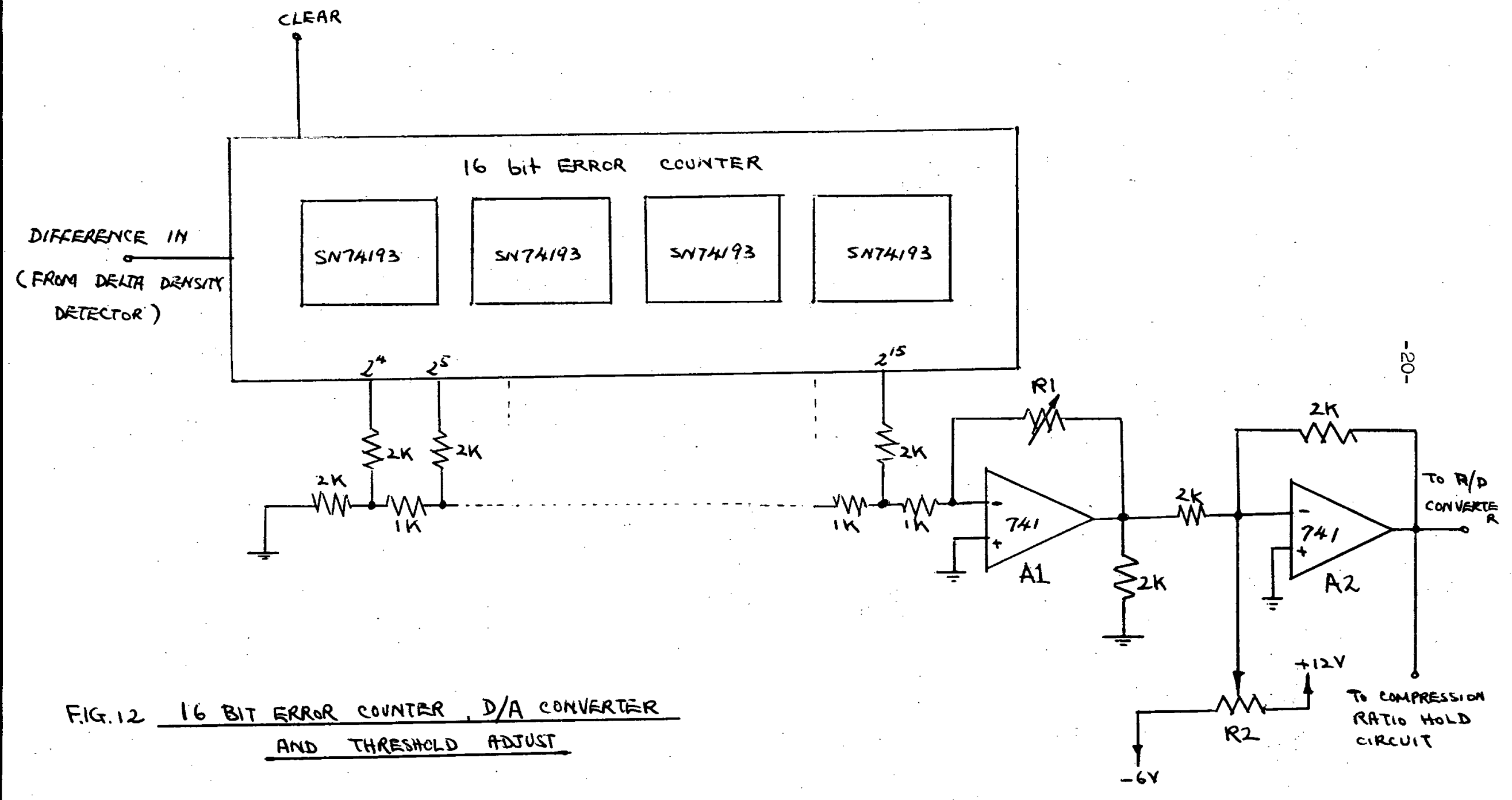


This output signal is in the form of a negative going ramp as shown in Figure 13. The counters are cleared at the beginning of each sampling period and at the end of this sampling period, the negative peak level of the ramp is sensed. This constitutes the delta density signal of the system. This signal goes to the A/D converter of the horizontal and vertical ramp generators and consequently controls the bandwidth of the video signal. This peak DC level is maintained until the next sampling period when the 16 bit error counter is cleared.

This delta density signal also goes to the compression ratio hold and threshold circuit which when an error is detected, will automatically hold the new compression ratio for about 5 seconds before sampling again. 
$-22-$

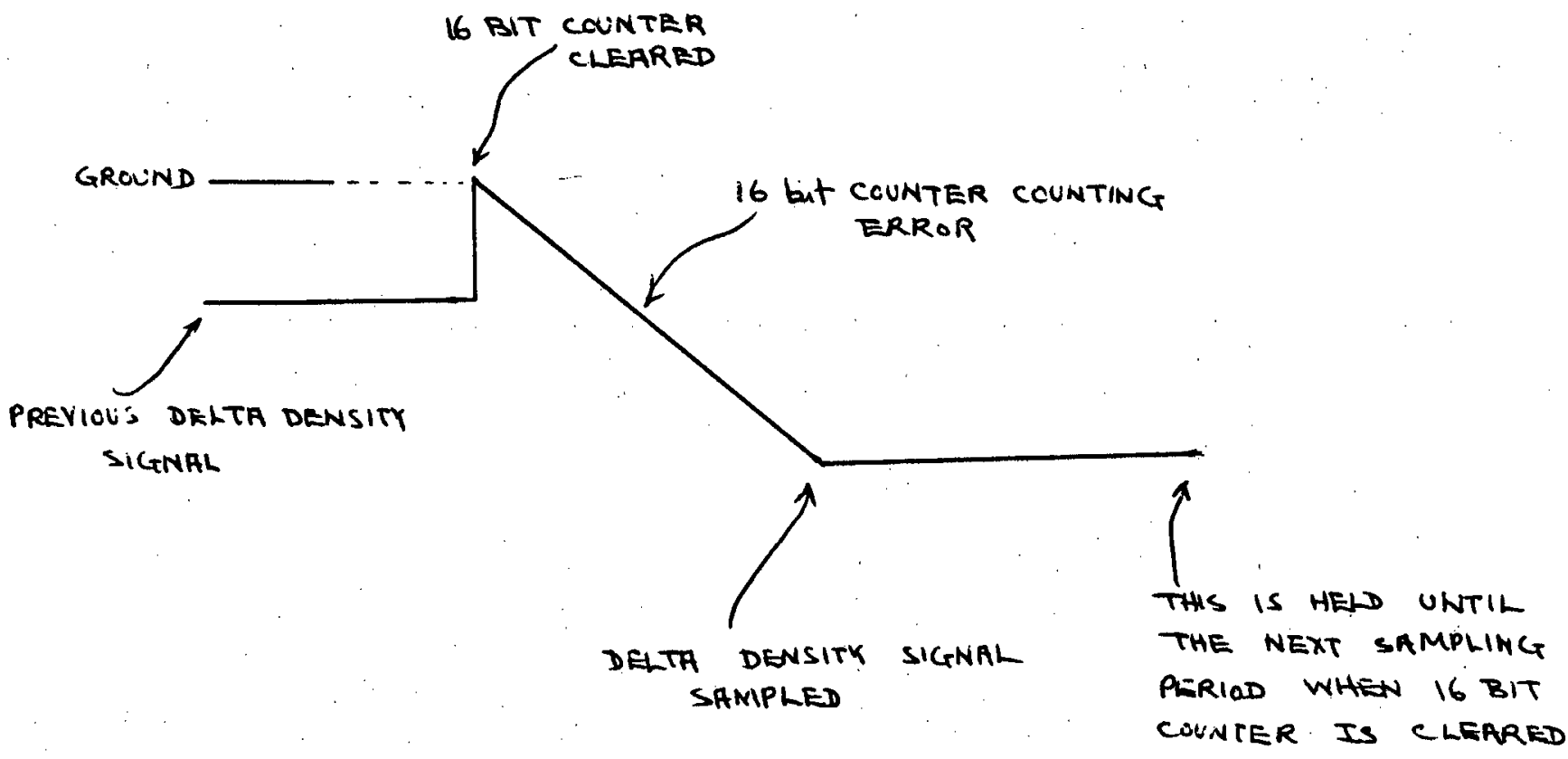

DELTA DENSITY SIGNAL RAMP

$$
\text { FIG. } 13
$$


Compression Ratio Hold and Threshold Circuit

The purpose of this card is to hold the system at a fixed bandwidth for about 5 seconds if the delta-density signal exceeds a certain threshold value (determined by the $2000 \mathrm{ohm}$ potentiometer). Otherwise the system will switch between bandwidths so rapidly that it will mean nothing to an observer of the demonstration.

The potentiometer is set so that if the delta density signal exceeds the value corresponding to a $2=1$ compression ratio, a "0" will appear at the $\bar{Q}$ output of the 5-sec-hold multivibrator after the next A/D strobe-in signal. This. "O" state, and hence the compression ratio, is maintained for 5 seconds. 


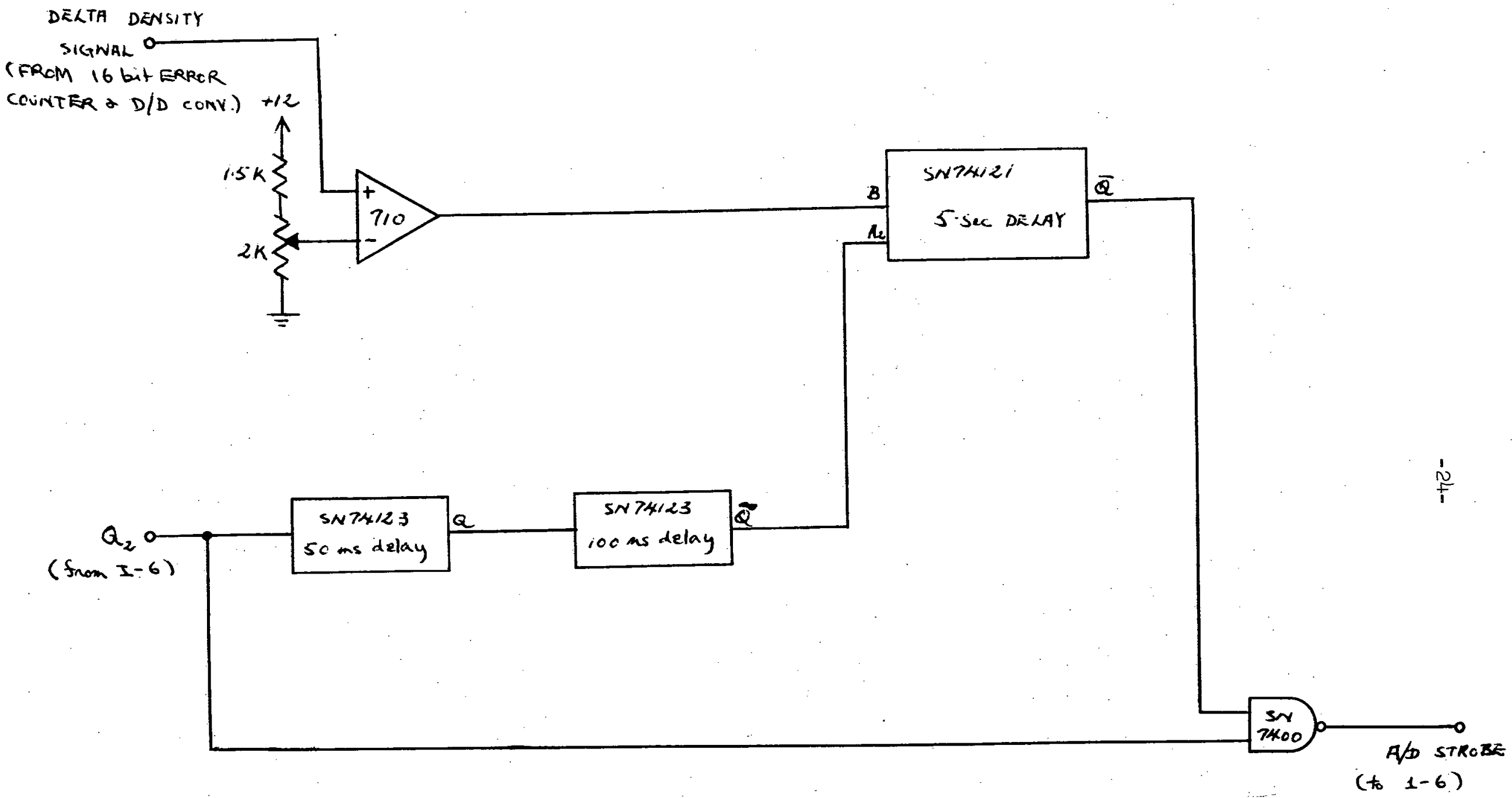

COMPRESSION RATIO HOND AND THRESHOLD CIRCUIT

$$
\text { FIG. } 14
$$

B. $T$. 
Variable Scan Camera

Changes had been made to the video pre-amplifier. In the original design, a gain control circuit was used to control the gain of the pre-amplifier depending on the scan rate. Ten ranges of scan rates were selected, each corresponding to a single value of pre-amplifier gain.

Upon completion of the system, it was found that the signal strength from the vidicon was quite independent of the scan rates and in order to simplify the system, the gain range discriminator (1469-266) was left out of the system. The camera and the video pre-amplifier function quite well under this modified design. 
Maintenance and Trouble. Shooting

\section{Maintenance}

To acertain the optimal operation of the system, a few adjustments to the varions subsystems are necessary from time to time. These are minor adjustments that involve the trimming of a few potentiometers and are usually done with the system on.

1. Deflection Amplifiers: When the picture quality start to deteriorate or when the camera axis is offcentered, the potentiometers on the horizontal and vertical deflection amplifiers on the camera should be adjusted. The driving ramps should have a peak-in-peak voltage of 30 volts and an average voltäge of 225 volts.

2. Delta Density Detector Circuit: The delta density signal detector may be misaligned occasionally and cause enatic operation of the machine in the automatic made. To align the recording/reading mechanism of the system, the following procedure is recommended. Return the system to the manual mode with $1: 1$ compression. Place a light screen $2-3$ feet in front of the camera. The light screen should have three vertical strips of black tape on it along its whole height. (This would facilitate synchronization of the oscilloscope.) Check the camera video to make sure that the vertical stripes are registered. Now adjust the potentiometers on the camera video amplifier and bias adjust circuits so that at the input of the disc the video sign is about 0.3 volt peak-to-peak biased at a level of about 1 volt. Then look at the output of the disc of the same channel and make the final adjustments so that the disc video is a fair resemblence of the camera video. Repeat for the other channel. Disconnect one channel from its read gate and adjust the input of the other channel to the $\mathrm{RF}$ amplifier and demodulator so that after demodulation a good copy of the camera video can be obtained. Repeat for the other channel. 


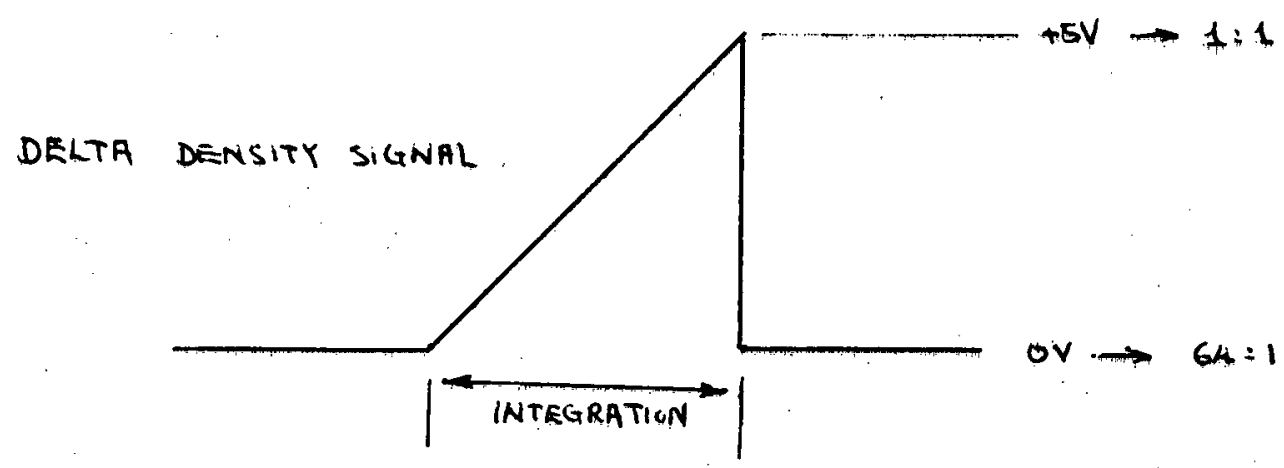

VOLTAGE RANGE OF DELTA DENSITY SIGNRL

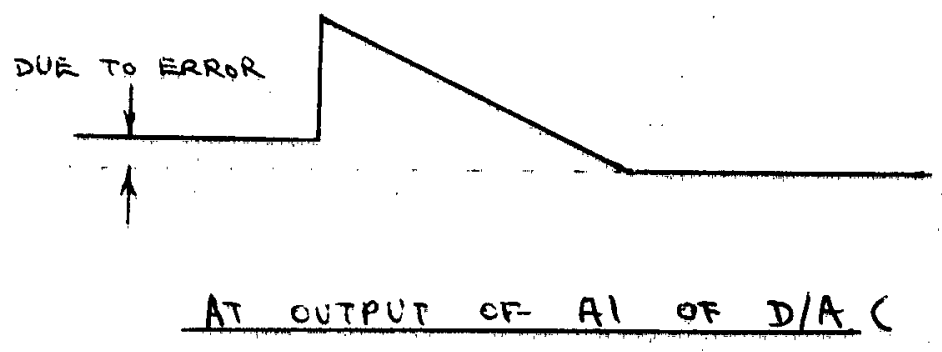

ADJUST RI AND R2 SO THAT:-

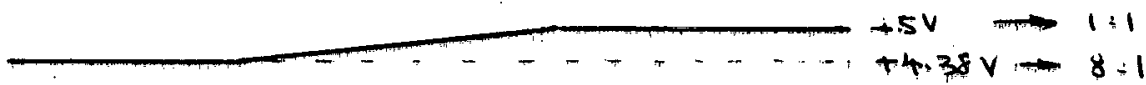

OUTPUT OF A2 (DELTA DENSITY SIGNAL)

ADJUSTMENTS FOR DELTA PENSITY SIGNAL

$F / G, 15$ 
Disconnect one channel from its read gate and adjust the input of the other channel to the RF amplifier and demodulation so that after demodulation a good copy of the camera video can be obtained. Repeat for the other channel.

Now adjust the potentiometers at the inputs of the differential comparators of the difference detector so that digitized versions of the video are obtained at the outputs.

Then turn the system to the automatic mode. Decide just what image change constitutes a "complete change of information" and set the peak of the corresponding delta density signal $\delta$ to +5 volt at the output of the second operational amplifier of the D/A converter using the level control. Set the gain adjust so that the minimum delta density signal corresponds to the maximum desired bandwidth compression ratio. It is recommended that this be $8: 1$ because at such a compression, the picture quality is still excellent. The A/D following this has a voltage range of 0 (corresponding to a ratio of 64 to 1 ) to +5 volts (corresponding to a ratio of $1: 1$ ). Figure 15 may help in making the alignment.

Trouble-shoot

This section is not on a systematic method for trouble-shooting the system. Rather it is a collection of ideas that one may find useful when trouble with the system does occur. It contains a partial list of the malfunctions, both minor and major, that had occurred and some adjustments or tests that may help to isolate the problem.

1. Owing to the very sophisticated method of generating and controlling the horizontal and vertical ramps, a lot of times, malfunction would involve 
part of the ramp generators and their allied circuits. Besides the power supplies, other locations to check would be the horizontal syn signal and the horizontal ramp control board (1469-2II). If deflection had failed, check the deflection amplifiers of the camera, the camera power supply (ripple in the $300 \mathrm{~V}$ supply would indicate malfunction in the supply board (1469-252), and the vidicon protection circuit (1469-280).

2. If there is deflection but no picture, first check whether the ring around the vidicon target had slipped, and then check the video pre-amplifier. Also check to see if the stage on which the vidicon is mounted had been displaced so that the camera lens does not focus on the vidicon.

3. If the picture is washed-out, try adjusting the potentiometer mounted in the rear of the cabinet.

4. If problems occur with the interlace, check the frame control circuits and the scan program control circuit. 


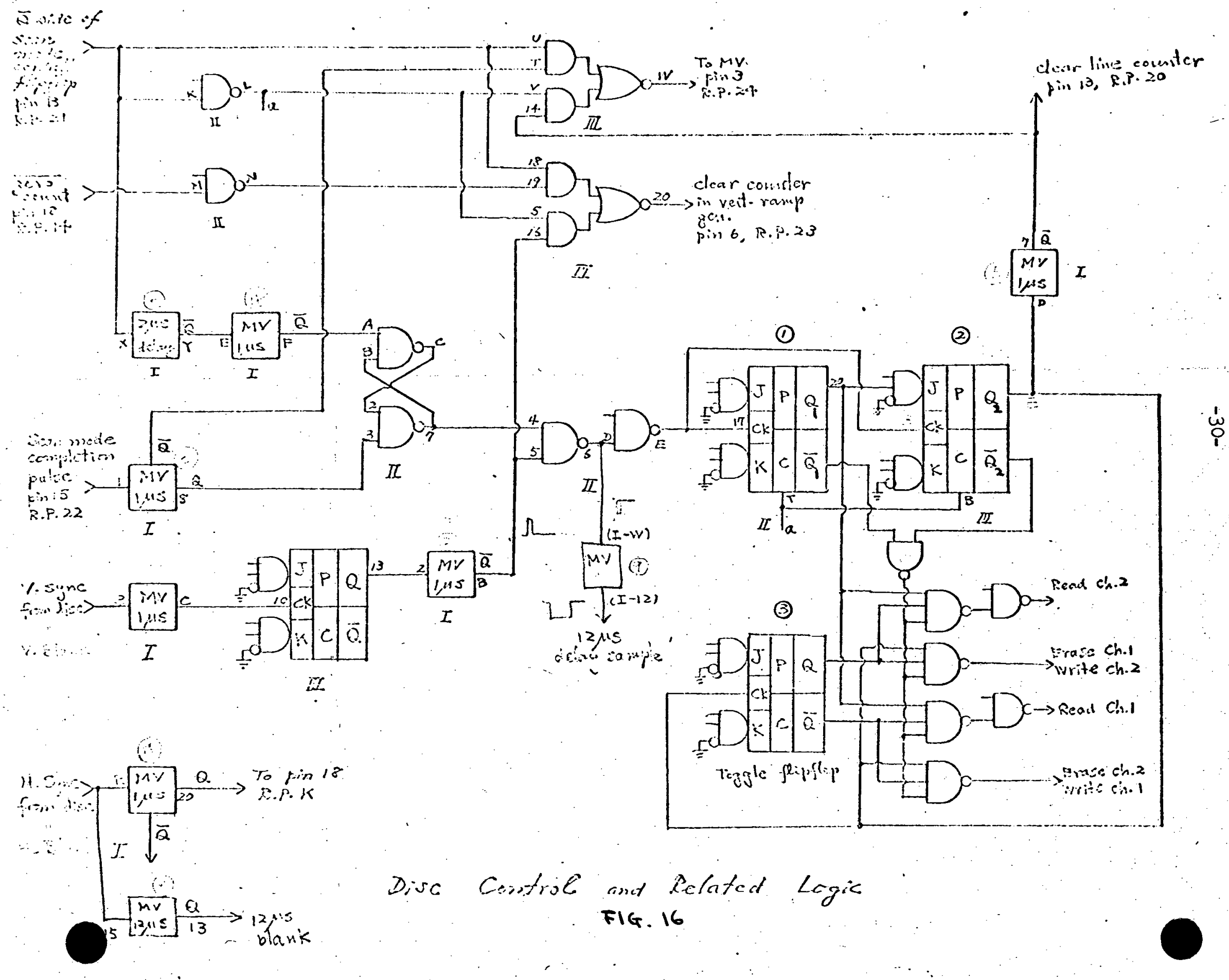



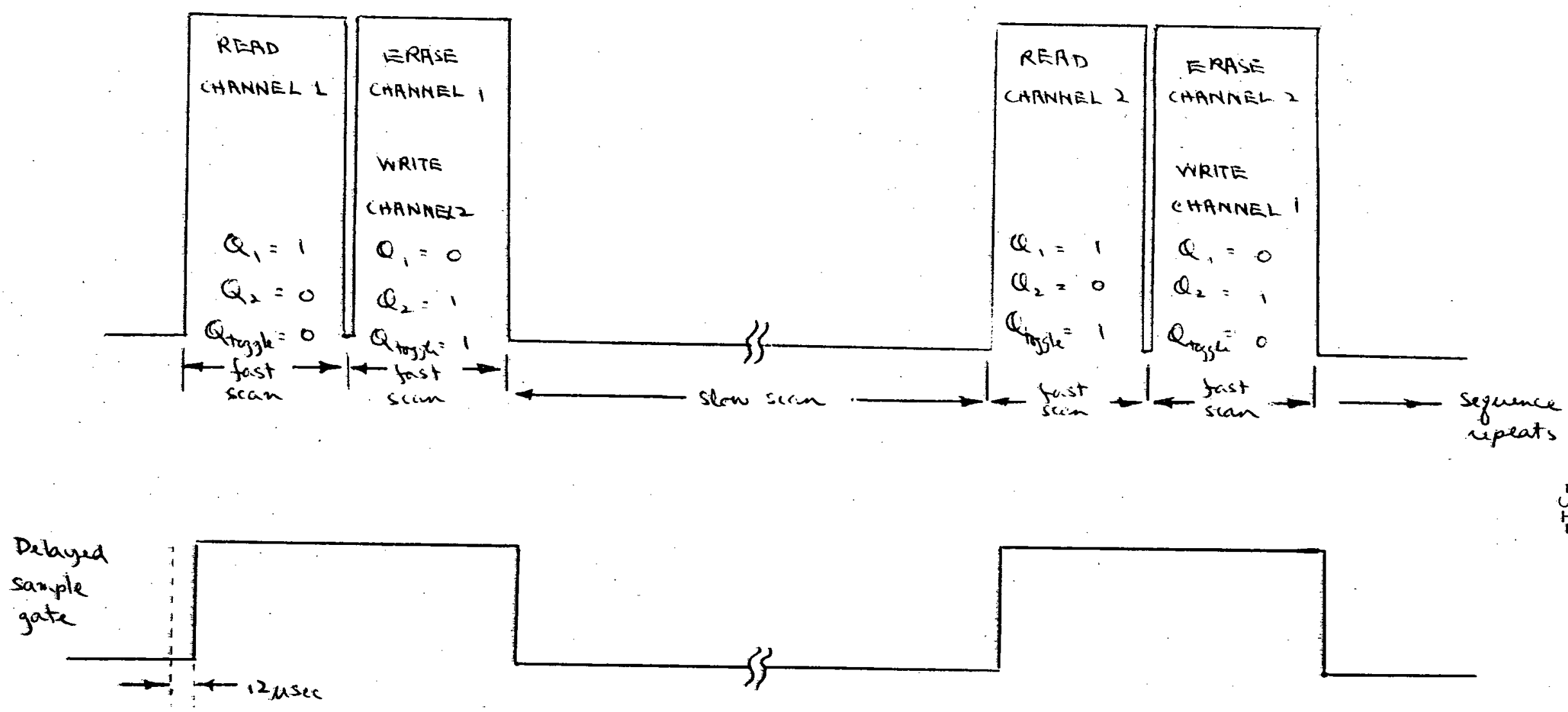

READ/WRITE/GRASE GATES CONTROL BY $Q_{1}, Q_{2}$ AND $Q$ tog 3 le FIG. IT 


\section{Appendix}

\section{A.I Rationalization of Digital Composition of Disc Video Vd and Camera Video $V$}

In the original design of the delta density detector, two analog signals Vd and $\bar{V}_{c}$ are added up with an operational amplifier and the resulting difference is integrated over one fast scan frame to produce the delta density signal. Such as design may be more accurate in a sense but because of the analog nature of this comparison process, both $V d$ and $\bar{V}_{c}$ have to be aligned so that for a. still picture both must have precisely the same DC level and magnitude at the input of the operational amplifier. If there is a slight DC offset for the operational amplifier or if one input has a.higher average DC, then an error would occur and would be integrated for an entire fast scan frame. Under certain circumstances, the error so introduced would be much larger than the actual total of the change in picture information. So the original design may be more accurate under the optimal condition, but sensitivity to information change suffers if this optimum operating condition is not attained.

In the present design, both Vd and $\bar{V}_{c}$ are digitized with differential amplifiers with adjustable threshold, and are then compared in a digital manner with an EXCLUSIVE-OR gate. In a sense, this means that all gray-levels are ignored and $V d$ and $\bar{V}_{c}$ are compared for their black-and-white levels. This also means that a slight change in light condition (and hence causing a shift in the gray level in the video signal) would not have too much effect on the digitized versions of $V d$ and $\vec{V}_{c}$. This is acceptable since a change in the light condition of the picture does not constitute a change in the picture information and so should not be acted upon as a change.

One other benefit of switching to a digital comparison is that the delta density detector is less sensitive to the accumulated built-in exror of the recording and comparing mechanism. Because the lower order bits of the 16 bit 
error counter are ignored, most of the error of the system that are not related to a change in picture information should be included in these lower order.bits, and so they do not enter into the generation of the delta density signal. 
A.2 Read/Write/Erase Gates Control

In the present scheme for read/write/erase, video information going into and out of the video disc is controlled by three flip-flops $Q_{1}, Q_{2}$ and $Q_{\text {toggle }}$ as shown in Figures 16 and 17 . The main point to note is that reading and writting are not simultaneously in order to avoid the high degree of intermodulation between adjacent tracks of the video disc. 


\section{A.3 Video Disc}

The following 8 pages contain diagrams of the video disc used in the VISTA system. Four tracks are available on this vide disc made by Colorado Video, but only to tracks are actually used in the system.

It is inportant that the VISTA system, and the video disc in particular, is not moved while the machine is running or else damage may be done to the disc.

This particular video disc is amost an exact copy of the disc used in the Tricolor Cartograph. While modifications had been done to the latter, the one used in VISTA had not been modified in any way. 


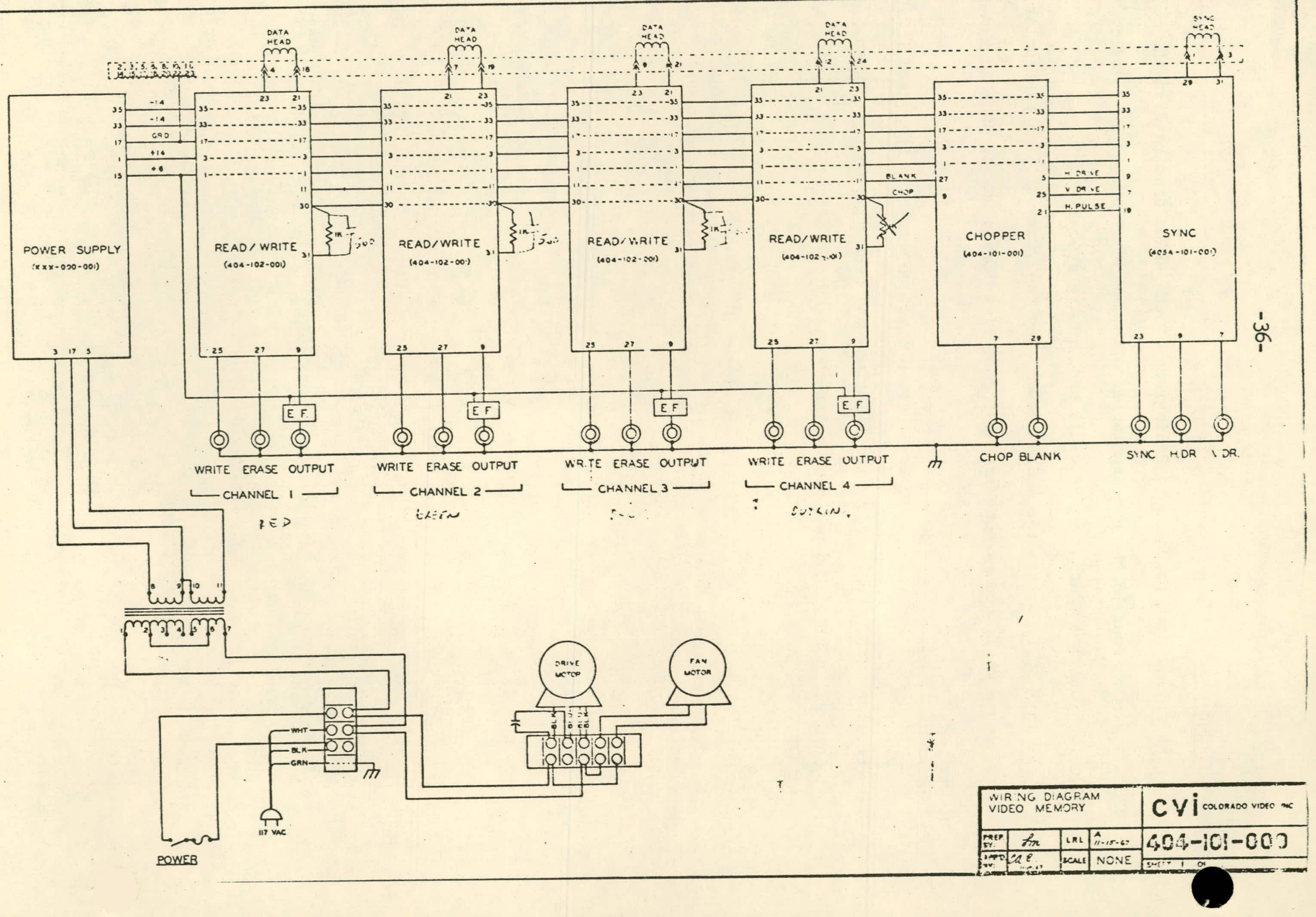




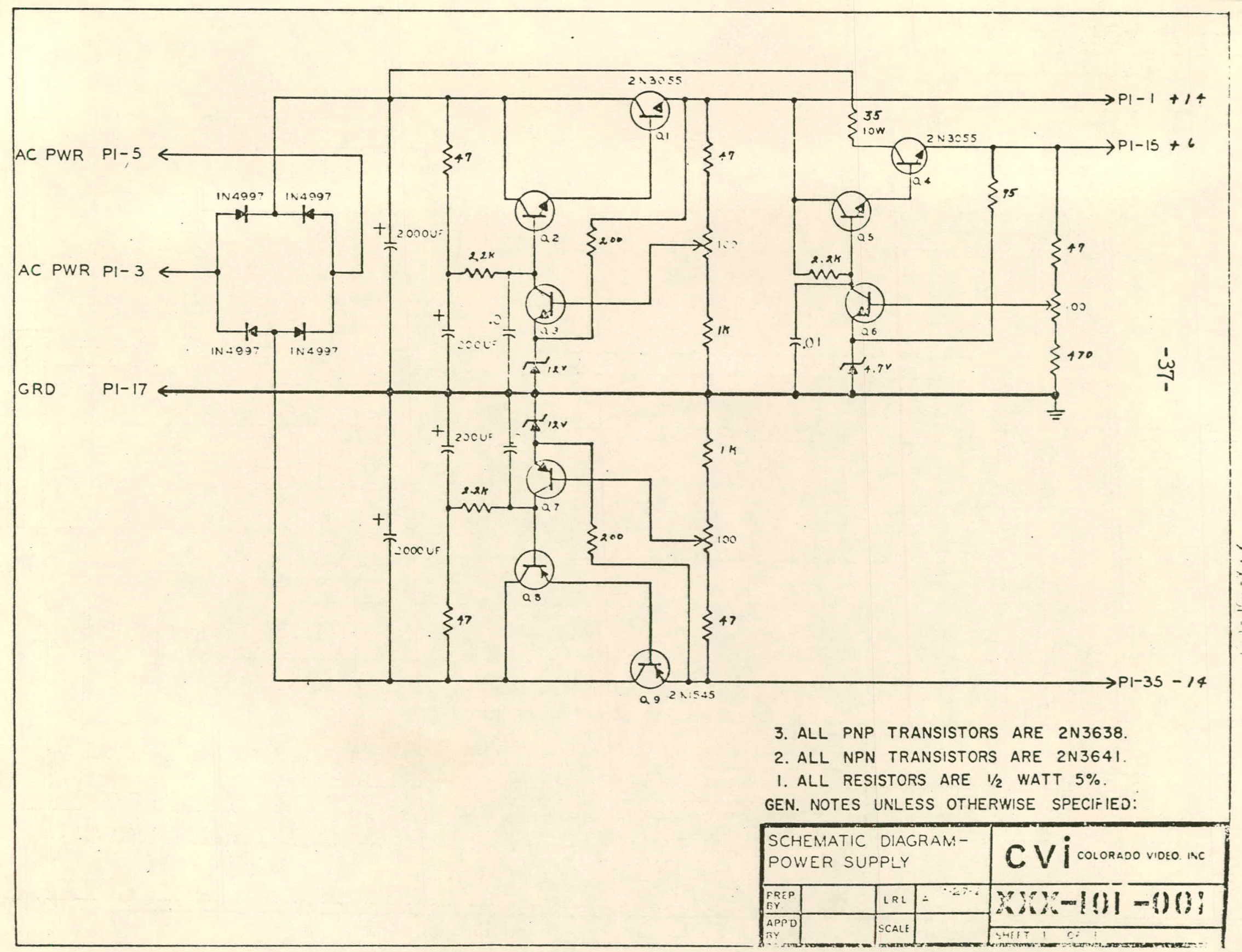




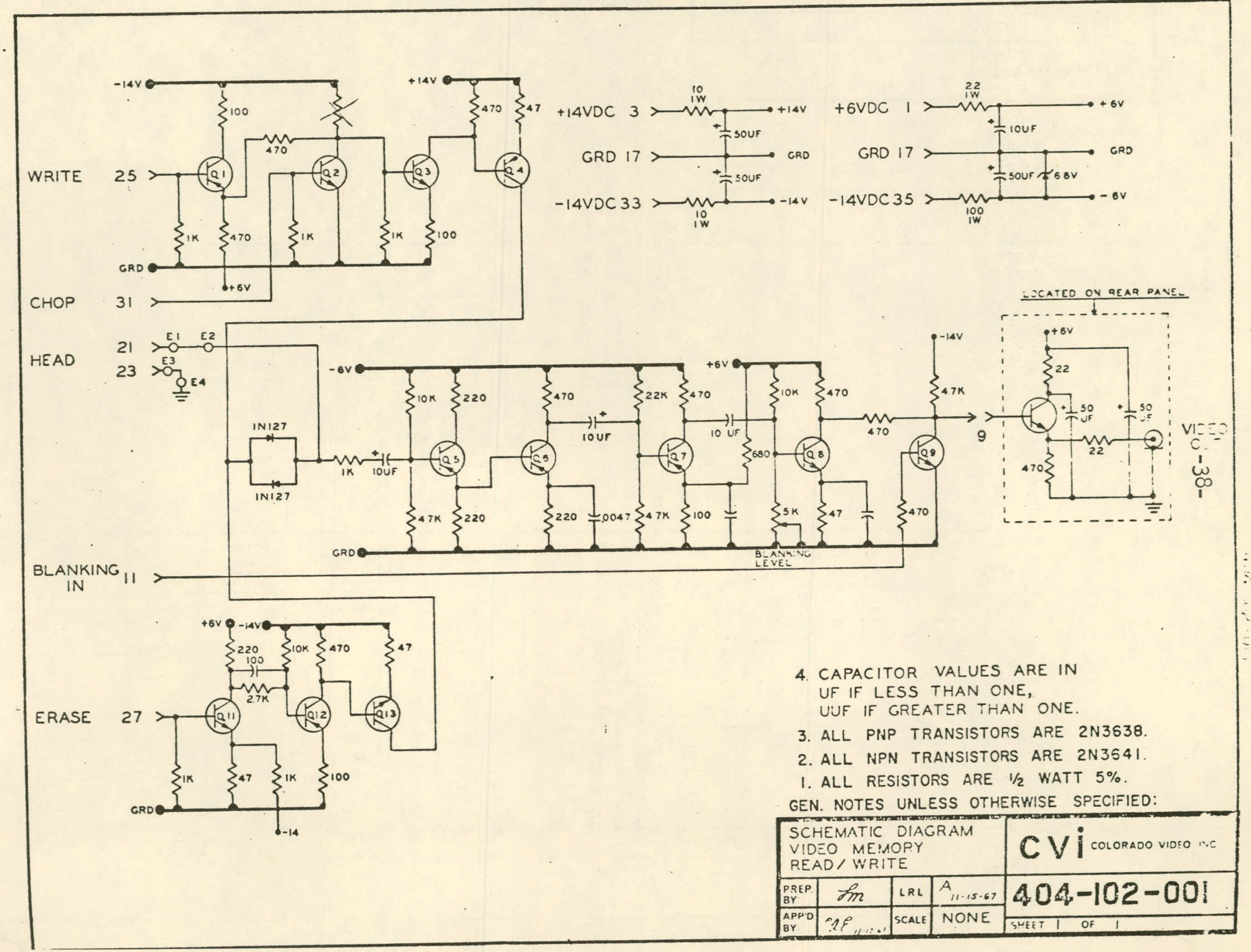




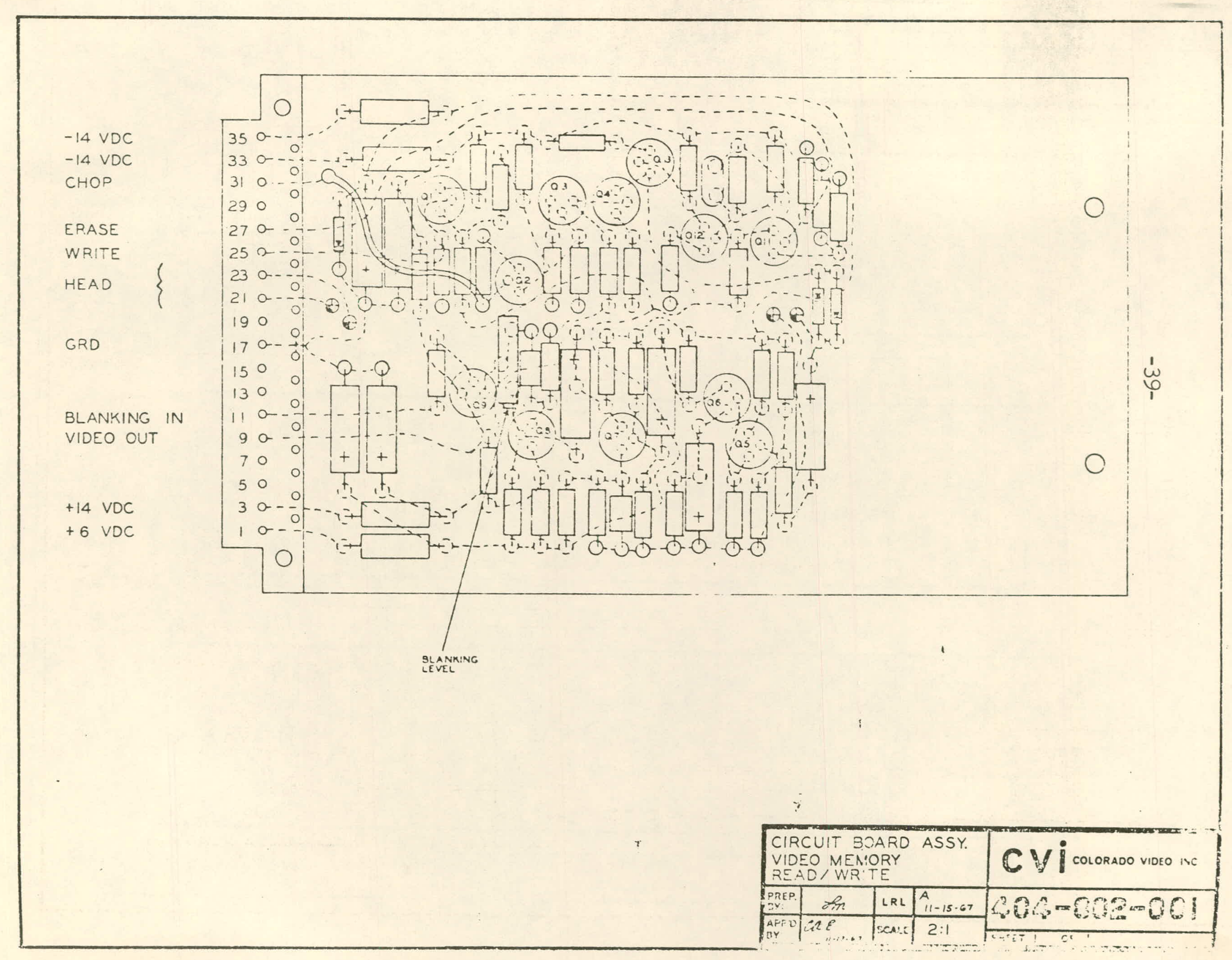




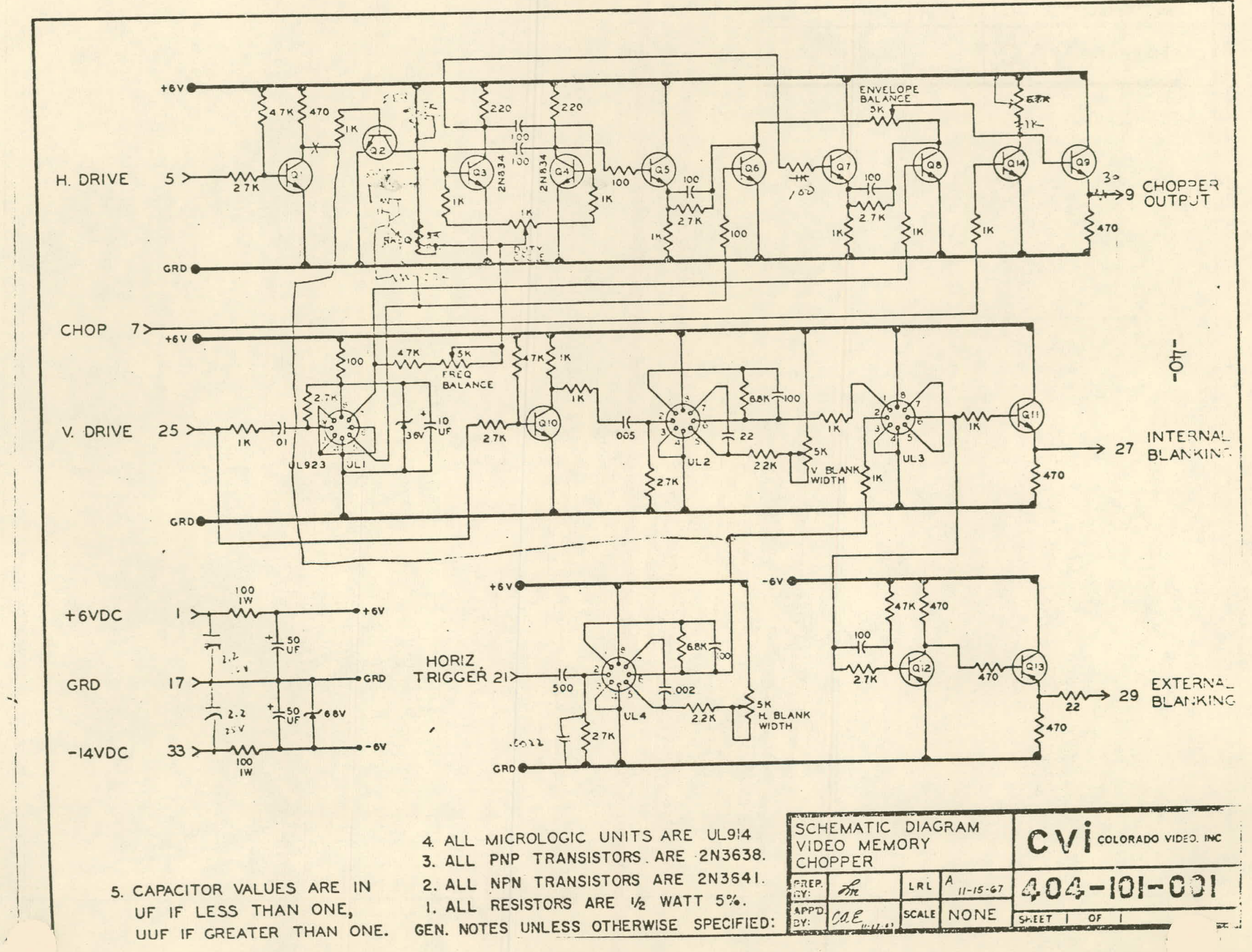




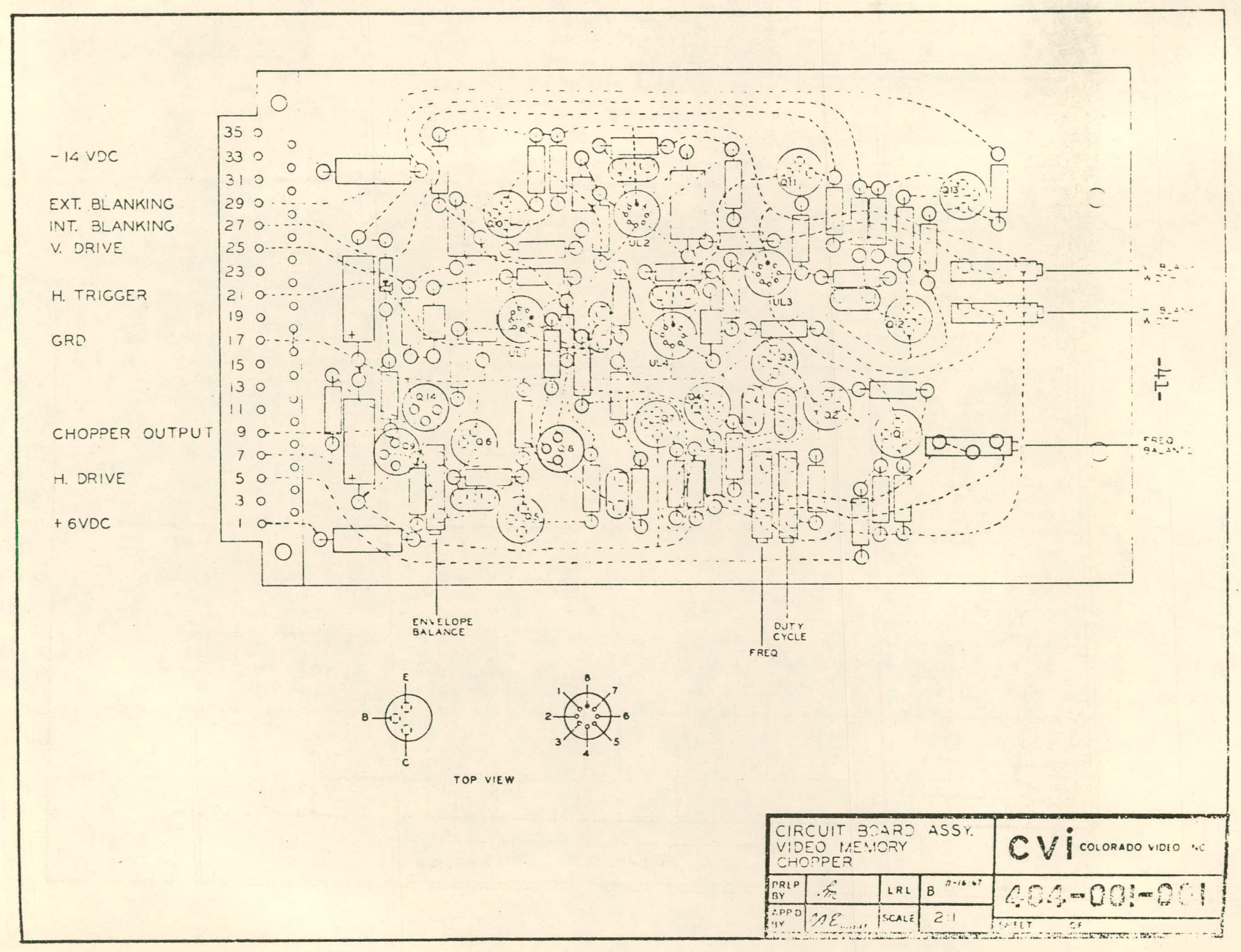




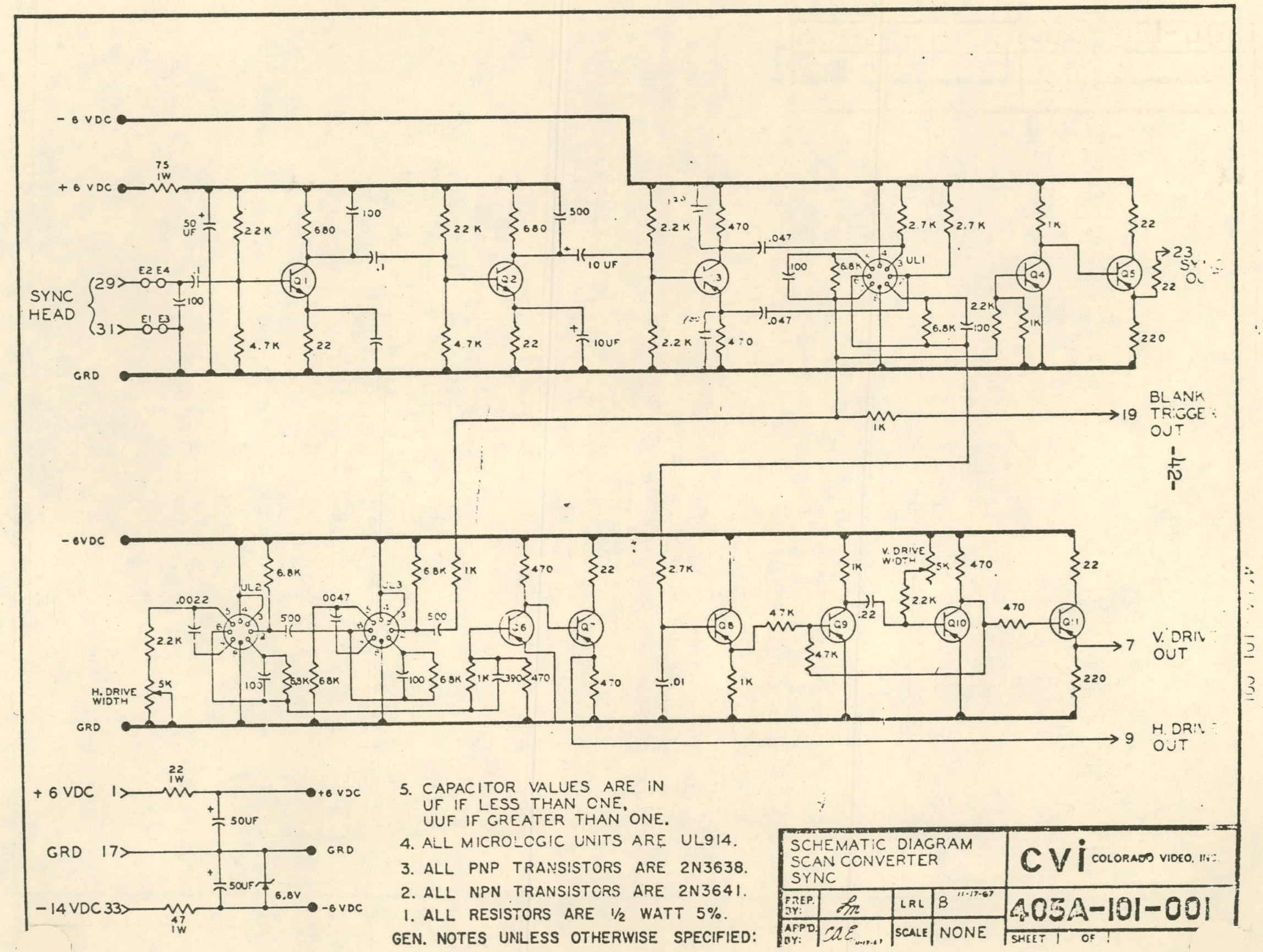




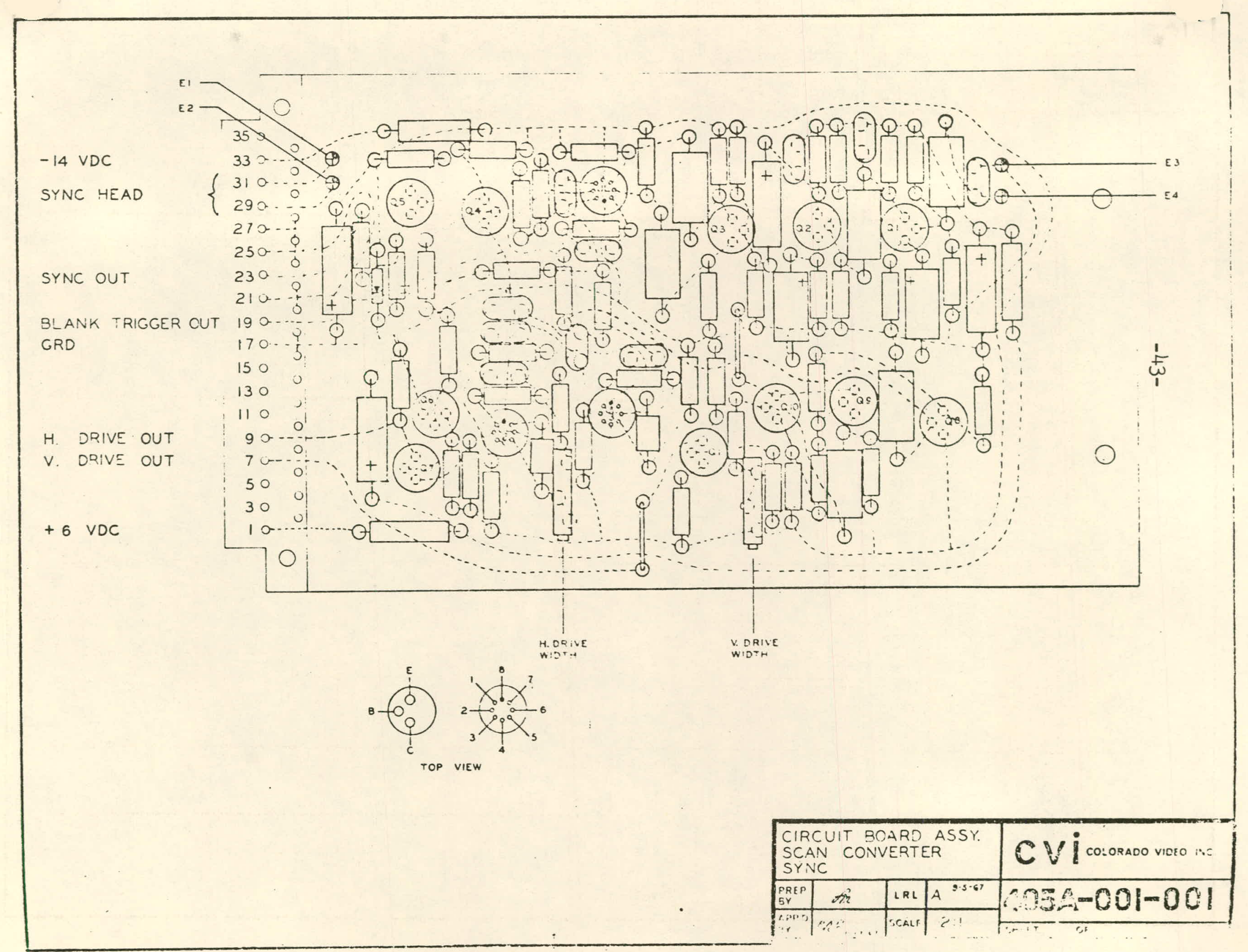




\begin{tabular}{|c|c|c|}
\hline \begin{tabular}{|l|l|} 
BIBLIOGRAPHIC DATA & 1. Report No. \\
SHEET & UIUCDCS $-R-72-524$ \\
\end{tabular} & 2 & 3. Recipient's Accession No. \\
\hline \multicolumn{2}{|l|}{ Title and Subtitle } & $\begin{array}{l}\text { 5. Report Date } \\
\text { June, } 1972\end{array}$ \\
\hline \multicolumn{2}{|l|}{ SUPPIEMENTARY INFORMATION ON VISTA } & 6. \\
\hline \multicolumn{2}{|l|}{ 7. Author(\$Ernard Tse } & $\begin{array}{l}\text { 8. Performing Organization Rept. } \\
\text { No. }\end{array}$ \\
\hline \multirow{2}{*}{\multicolumn{2}{|c|}{$\begin{array}{l}\text { 9. Performing Organization Name and Address } \\
\text { Department of Computer Science } \\
\text { University of Illinois } \\
\text { Urbana, Illinois } 61801\end{array}$}} & 10. Project/Task/Work Unit No. \\
\hline & & $\begin{array}{l}\text { 11. Contract/Grant No. } \\
46-26-15-301\end{array}$ \\
\hline \multirow{2}{*}{$\begin{array}{l}\text { 12. Sponsoring Organization Name and Address } \\
\text { Department of Computer Science } \\
\text { University of Illinois } \\
\text { Urbana, Illinois } 61801\end{array}$} & & $\begin{array}{l}\text { 13. Type of Report \& Period } \\
\text { Covered } \\
\text { Supplementary }\end{array}$ \\
\hline & & 14. \\
\hline
\end{tabular}

15. Supplementary Notes

16. Abstracts

VISTA, the Variable Interlace System for Television Applications system, is a system that compresses the bandwidth of a television signal according to the rate of change of information that it is carrying. The system determines automatically the amount of information that has changed since the previous sampling period and select one of sixty-four possible scanning rates commensurate with this change.

17. Key Words and Document Analysis. 17a. Descriptors

VISTA

Variable Interlace System for Television Applications

as.

17b. Identifiers/Open-Ended Terms

7c. COSATI Field/Group

18. Availability Statement

\begin{tabular}{|l} 
19. Security Class (This \\
Report) \\
UNCLASSIFIED \\
\hline $\begin{array}{l}\text { 20. Security Class (This } \\
\text { Page } \\
\text { UNCLASSIF IED }\end{array}$
\end{tabular}

21. No. of Pages 48.

22. Price 